\title{
Testing a Landsat-based approach for mapping disturbance causality in U.S. forests
}

Authors: Todd A. Schroeder a*, Karen G. Schleeweis b, Gretchen G. Moisen b, Chris Toney c, Warren B. Cohen ${ }^{d}$, Elizabeth A. Freeman ${ }^{b}$, Zhiqiang Yang e, Chengquan Huang ${ }^{f}$

a USDA Forest Service, Southern Research Station, Knoxville, TN 37919, USA, (taschroeder@fs.fed.us), 865-862-2034 (phone)

b USDA Forest Service, Rocky Mountain Research Station, Ogden, UT 84401, USA, (gmoisen@fs.fed.us), (kgschleeweis@fs.fed.us), (eafreeman@fs.fed.us)

c USDA Forest Service, Rocky Mountain Research Station, Missoula, MT 59808, USA, (christoney@fs.fed.us)

d USDA Forest Service, Pacific Northwest Research Station, Corvallis, OR 97331, USA, (warren.cohen@oregonstate.edu)

e Department of Forest Ecosystems and Society, Oregon State University, Corvallis, OR 97331, USA, (zhiqiang.yang@oregonstate.edu)

f Department of Geography, University of Maryland, College Park, MD 20742, USA, (cqhuang@umd.edu)

${ }^{*}$ Corresponding author

Keywords: Forest disturbance mapping, Causal agents, Landsat time series, Empirical modeling, Random Forests, Remote sensing 


\begin{abstract}
In light of Earth's changing climate and growing human population, there is an urgent need to improve monitoring of natural and anthropogenic disturbances which effect forests' ability to sequester carbon and provide other ecosystem services. In this study, a two-step modeling approach was used to map the type and timing of forest disturbances occurring between 1984 and 2010 in ten Landsat scenes located in diverse forest systems of the conterminous U.S. In step one Random Forest (RF) models were developed to predict the presence of five forest disturbance agents (conversion, fire, harvest, stress and wind) and stable (i.e. undisturbed) forest. Models were developed using a suite of predictors including spectral change metrics derived from a nonparametric shape-restricted spline fitting algorithm, as well as several topographic and biophysical variables which potentially influence the initiation and/or spread of forest disturbance agents. Step two involved applying a rule-based model to the spectrally-based shape parameters (e.g. shape type, year and duration) to assign a year to the disturbance types and locations predicted in step one. Out of bag (OOB) predictions from RF showed that across the ten scenes, overall agreement was highest when only causal agent was considered (avg $=80 \%, \min =69 \%$, $\max =86 \%$ ), and was lowest when both agent and year (within \pm 1 of the reference date) were required to be correct $(\operatorname{avg}=71 \%, \min =56 \%, \max =80 \%)$. Across scene omission and commission errors for fire and stable forest classes were mostly around $10 \%$ to $20 \%$, respectively. Harvests were also modeled well, as five of nine test scenes had error rates less than 26\%. Accuracy of the wind and stress classes were much more variable with model errors ranging from $24 \%$ to $88 \%$. The years assigned by the rule-based model were reasonably accurate, as $88 \%$ of all disturbances were assigned a year that fell within \pm 2
\end{abstract}


years of the reference date. Fire disturbances were assigned the correct year $78 \%$ of the time, followed by harvest (69\%) and conversion (54\%). Although $17 \%$ and $63 \%$ of wind and stress disturbances were under-estimated by 5 or more years, the impact on overall accuracy was nominal given these two classes only accounted for roughly $5 \%$ of all disturbances. Our results also revealed that causal agent models summarized to broader disturbed/not disturbed classes were as accurate as models specifically constructed to predict binary disturbance, thus there appears to be no advantage to modeling disturbance prior to assigning causality. A relative evaluation of mean decrease in accuracy from RF showed that although a wide range of predictor variables contributed to the successful modeling of causal agents and stable forest (e.g. patch metrics, forest occurrence, and topography), disturbance variables (e.g. MTBS) and spectral change metrics (e.g. absolute and relative magnitude) were by far the most important. Modeled causality maps and annual disturbance rates were examined and found to be in good agreement with existing literature and other published data sets. Lastly, results are used to make recommendations for mapping forest disturbance agents nationally across the U.S. 


\section{Introduction and Objectives}

Forests support life and human society by providing critical ecological, social and economic benefits, including clean water, oxygen, wildlife habitat, recreation, carbon storage and a variety of forest products. In the United States, forests occupy roughly one third of the total land base, and although the amount of forestland has remained relatively stable over the last century (Oswalt et al., 2014) there is growing evidence that rising temperatures have led to more frequent and intense forest disturbance events (Westerling et al., 2006; van Mantgem, 2009; Allen et al., 2010; Pearson et al., 2012; Cohen et al., 2016). Given that both anthropogenic and natural disturbances shape forest composition, structure, and function, there will likely be increasing socioeconomic consequences associated with widespread declines in forest health (Weed et al., 2013; Anderegg et al., 2013). Recent studies have already found evidence of reduced tree growth (Williams et al., 2010), increases in species turnover dynamics (Zhu et al., 2014) and declines in water quantity (Mikkelson et al., 2011) and quality (Mikkelson et al., 2013) in response to climate-induced forest die-off. Additionally, increasing rates of disturbance will also pose significant challenges to land managers who seek adaptation strategies to ensure sustainability, genetic diversity and resiliency of forest ecosystems (Spittlehouse and Stewart, 2003).

With temperatures (IPCC, 2014) and human populations (Raftery et al., 2012) both projected to rise in the future, forests will continue to be rapidly transformed by climate and human-induced forcings. As these changes could potentially trigger shifts and or loss of human and biotic populations (Aral, 2014), there is an urgent need to advance our understanding of the causes and consequences of disturbance through space and time. 
Since disturbance occurs at a variety of spatial and temporal scales, and across a range of magnitudes, an improved monitoring strategy will require some combination of field measurements (which can identify localized impacts including below canopy and understory effects) and repeated observations from remote sensing satellites (which can detect upper canopy effects over large areas on an annual basis). Ideally, field plots and satellite image time series will form an integrated system where observations from each data stream are leveraged in a way that helps inform or improve estimates from the other (e.g. see Schroeder et al., 2014). Thus, in addition to improving field data there are several reasons for also seeking better map-based disturbance products as they facilitate spatial pattern analysis, can reduce fine scale errors in spatially explicit biogeochemical models (e.g. BiomeBGC, Carnegie-Ames-Stanford Approach or CASA, also see Williams et al., 2014 and Gu et al., 2016), and can be used to develop strata to reduce variance of plot-based estimates via post-stratification (McRoberts et al., 2005). Therefore the focus of this paper is on producing improved disturbance maps which can accurately resolve the spatiotemporal patterns of change caused by different agents over the last quarter century.

To date, several new automated mapping algorithms have been developed which are capable of detecting disturbance from the spectral signal taken from multiple Landsat images (e.g. Vegetation Change Tracker or VCT, Huang et al., 2010a; Landsat-based detection of Trends in Disturbance and Recovery or LandTrendr, Kennedy et al., 2010; Continuous Change Detection and Classification or CCDC, Zhu et al., 2012; and others including Vogelmann et al., 2012 and Brooks et al., 2014). Though these algorithms are applied to image stacks of varying density (e.g. annual stacks of growing season images vs. 
denser stacks using all available images) and use different statistical approaches (e.g. adaptive thresholding, linear segmentation, Fourier curve fitting) they all tend to output maps which resolve the timing and, in some cases, the spectral magnitude of disturbance. Although several studies have mapped causal agents in the U.S. with Landsat scale data, most have been limited to smaller geographic areas. For example, Schroeder et al. (2012) mapped fire and harvest classes in one Landsat scene in the Canadian boreal forest, Neigh et al (2014a) produced maps of insect and harvest classes for four Landsat scenes covering the deciduous forests of the north central U.S. and more recently Neigh et al. (2014b) and Kennedy et al. (2015) produced maps of multiple agent classes for several Landsat scenes in the Pacific Northwestern U.S. Owing to the difficulty of separating different change types with purely automated algorithms, the one commonality shared among the aforementioned studies is that they all used some type of supervised approach (e.g. maximum likelihood, Random Forest) to map causal agents. The relative success of these studies suggests that different types of forest disturbance invoke distinct enough spectral patterns to be accurately separated into unique classes. Yet, several opportunities for advancement remain.

For example, no single spectral band or index consistently responds to all types of disturbance. Schroeder et al. (2012) demonstrated that in the boreal forests of Canada, spectral data from Landsat's shortwave-infrared region (i.e. band 5) could be used to accurately separate wildfires and clearcut harvests while data from near-infrared indices (e.g. NDVI) could not. More recently, Cohen et al. (2016) highlighted the need for analysts to view multiple spectral bands and indices when manually interpreting Landsat data for 
the presence of disturbance. This study also points out that automated algorithms which use only one spectral band or index (Vogelmann et al., 2012; Kennedy et al., 2010) often have higher omission and commission mapping errors.

Another opportunity derives from the fact that certain types of forest disturbance are influenced by topographic and biophysical factors which are not inherently captured by optical remote sensing data (Reams et al., 2010). For example, topographic orientation can influence the intensity and spread of wild-fires (Linn et al, 2007), can exacerbate drought conditions leading to higher rates of beetle-induced tree mortality (Christiansen et al, 1987), and can increase a stands susceptibility to lightning strikes and wind-throw (Foster, 1988), thus there are several reasons why including spatial variables which describe local topography (e.g. elevation, slope and aspect derived from DEM's), patch geometry (e.g. harvests tend to be smaller and geometrically shaped vs. fires which are often bigger and irregularly shaped) and species occurrence (e.g. Ruefenacht et al., 2008) may help improve the classification of certain disturbance types (e.g. see Hermosilla et al., 2015).

As other countries have begun producing regional and national scale maps of various forest disturbance agents (e.g. see Hermosilla et al., 2015 - Canada; Haywood et al., 2016 Australia; Potapov et al., 2015 - Europe) there is high demand for a similar, consistently developed U.S. product. Therefore, the overarching objective of this paper is to test a systematic approach which can integrate information from Landsat and other data sources to produce change maps in different forest regions found across the U.S. Extending the work performed under the National Aeronautics and Space Administration (NASA) and 
North American Carbon Program's (NACP), North American Forest Dynamics (NAFD)

project (Goward et al., 2008), a series of pilot tests were conducted over ten Landsat scenes representing diverse forest types and disturbance regimes found across the country. Our objectives were to:

1. Evaluate the potential for mapping five different forest disturbance agents (conversion, fire, harvest, stress and wind) and for mapping areas of undisturbed (or stable) forest using a systematically employed, empirical modeling approach.

2. Determine if complex agent models are as accurate at locating non-attributed change as simpler, binary disturbed/not disturbed (DND) models.

3. Determine which predictor variables are most useful for modeling forest disturbance agents at the national scale.

4. Make recommendations to enhance operational development of a consistent, U.S. national forest disturbance mapping product.

\section{Methods}

\subsection{Study area}

To ensure our mapping approach was tested in a variety of different environments we used a national MODIS-based forest type map (Ruefenacht et al., 2008) and a national integrated forest disturbance map (see Schleeweis et al., 2013, Figure 5,) to select 10 Landsat scenes which represent a diverse array of forest types and disturbance processes (e.g. harvesting, fire, insect, hurricane, and urbanization). We divided the 10 scenes so that both the eastern and western regions of the country were equally represented. The locations of the selected World Reference System (WRS2) Landsat path rows are shown in Figure 1. The boundaries 


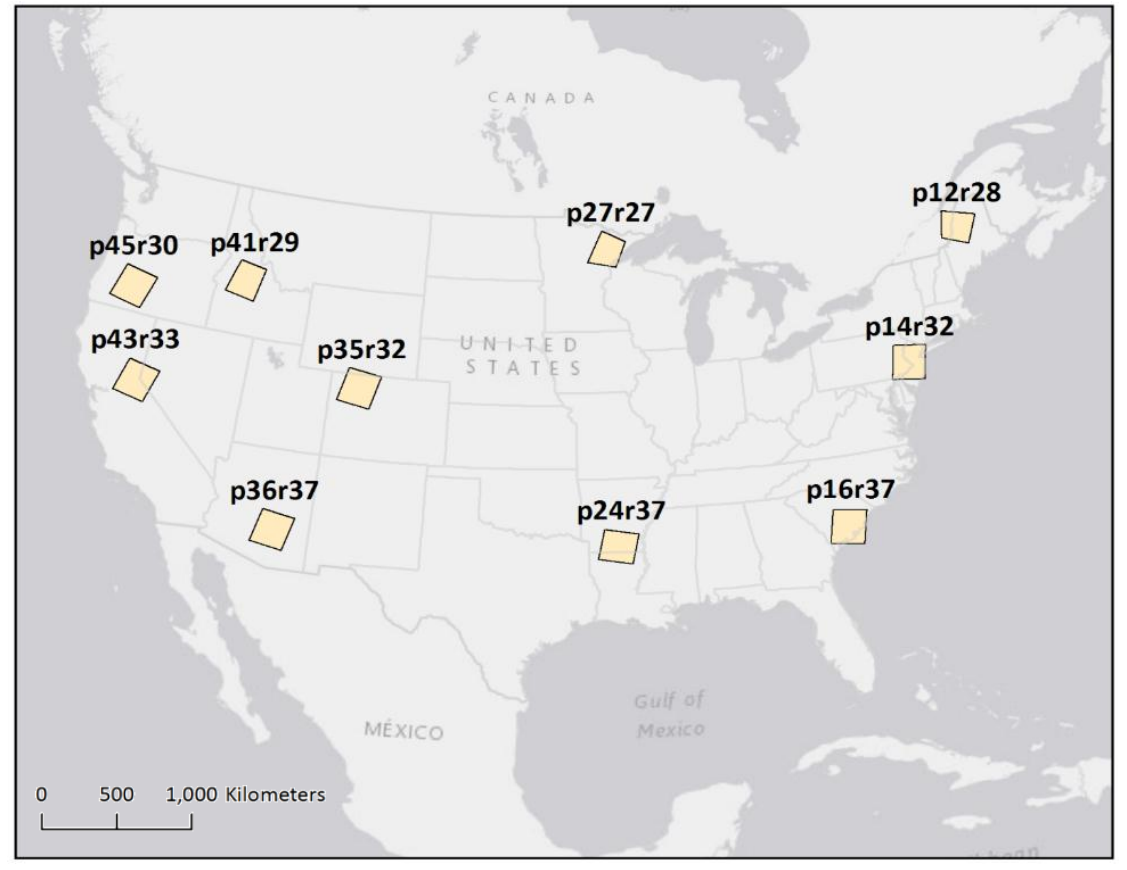

Figure 1. Location of the ten Landsat test scenes used in this study. The scene boundaries reflect the coincident area shared by all the images in each time series stack.

of each scene reflect the coincident area shared by all the Landsat images in each time series stack (described later in Section 2.2.2.). Estimates of total forest cover (derived as the percentage of forest area divided by the total scene area from initial VCT maps), and major species groups and disturbance processes found in each Landsat test scene are summarized in Table 1.

\subsection{Data}

\subsubsection{Reference data}

Since disturbance is a rare event which typically impacts less than $3 \%$ of forest area per year (Masek et al., 2013) two types of sampling were used to record reference information 
Table 1. Description of the forest cover (from Vegetation Change Tracker, VCT Huang et al. 2010a), forest species groups (from Ruefenacht et al., 2008), and disturbance processes (from Schleeweis et al. 2013) found in each of the ten Landsat test scenes.

\begin{tabular}{|c|c|c|c|c|c|c|}
\hline Region & Path/Row & State (s) & Forest (ha) & $\%$ Forest & Major Forest Species Group & Major Disturbance Processes \\
\hline East & p12r28 & ME & $2,075,725$ & 92 & Maple/Beech/Birch; Spruce/Fir & Harvest \\
\hline East & $\mathrm{p} 14 \mathrm{r} 32$ & $\mathrm{PA} / \mathrm{NJ}$ & $1,734,740$ & 60 & Loblolly/Shortleaf Pine; Oak/Hickory & Harvest, Insect, Urbanization \\
\hline East & p16r37 & SC & $1,752,164$ & 59 & Loblolly/Shortleaf Pine; Oak/Gum/Cypress & Harvest, Hurricane, Fire, Urbanization \\
\hline East & $\mathrm{p} 24 \mathrm{r} 37$ & AR/LA & $2,298,087$ & 83 & Loblolly/Shortleaf Pine; Oak/Gum/Cypress; Oak/Hickory & Harvest, Urbanization \\
\hline East & p27r27 & MN & $1,895,981$ & 87 & Aspen/Birch; Spruce/Fir & Harvest, Insect, Urbanization \\
\hline West & p35r32 & $\mathrm{CO}$ & 306,502 & 33 & Fir/Spruce/Mountain Hemlock; Aspen/Birch; Pinyon/Juniper & Insect, Fire, Harvest \\
\hline West & p36r37 & $A Z$ & 767,817 & 26 & Pinyon/Juniper; Western Oak; Ponderosa Pine & Fire, Urbanization \\
\hline West & $\mathrm{p} 41 \mathrm{r} 29$ & ID & $1,516,895$ & 60 & Douglas-fir; Fir/Spruce/Mountain Hemlock; Lodgepole Pine & Fire, Insect \\
\hline West & p43r33 & $\mathrm{CA} / \mathrm{NV}$ & $1,287,693$ & 43 & California Mixed Conifer; Fir/Spruce/Mountain Hemlock; Pinyon/Juniper & Harvest, Fire, Insect, Urbanization \\
\hline West & $\mathrm{p} 45 \mathrm{r} 30$ & OR & $1,846,855$ & 62 & Douglas-fir; Fir/Spruce/Mountain Hemlock; Ponderosa Pine & Harvest, Insect, Fire \\
\hline
\end{tabular}

for each of the ten Landsat test scenes. First, using an initial VCT map we randomly distributed 240 "probabilistic" sample plots across areas mapped as stable forest (i.e. areas of forest that remained undisturbed across the entire time series) and disturbed forest. Next, these one-pixel sample plots were analyzed by a human interpreter using the TimeSync reference data collection protocol outlined in Cohen et al. (2010). Briefly, this process involved using a trained analyst to manually record forest disturbances based on evidence gleaned from simultaneous inspection of annual Landsat images and spectral trajectories, high resolution aerial photos (e.g. National Aerial Imagery Program or NAIP, Google Earth) and ancillary GIS data, from the Monitoring Trends in Burn Severity (MTBS, Eidenshink et al., 2007) and LANDFIRE (Vogelmann et al., 2011) programs. Since areas disturbed prior to the start of the time series (referred to as recovery), and other infrequently observed disturbances types (described below) were excluded from the analysis some scenes had slightly fewer than 240 probabilistic samples. 
Second, a set of "supplemental" disturbance observations were derived using ancillary data from the LANDFIRE events database (http://www.landfire.gov/publicevents.php), U.S. Forest Service - Forest Inventory and Analysis (FIA; https://www.fia.fs.fed.us/) plots, and in some cases from purposive sampling of known disturbance areas. The FIA plots and LANDFIRE pixels that agreed with an initial VCT disturbance map were then inspected by a human interpreter to ensure type and timing of disturbance were correctly assigned, and to ensure there was a minimum of $1,500 \mathrm{~m}$ (or 50 pixels) between plots to avoid autocorrelation issues. Initial trials indicated that selecting too many pixels from the same disturbance patch negatively impacted model accuracy. Overall, the number of supplemental disturbance samples selected for each test scene varied based on the availability of the ancillary data sets (e.g. LANDFIRE data is more available on federal lands, thus there is more data available for the 5 western scenes), as well as the level of analyst tuning required to minimize effects of over sampling the polygon data.

The two types of sampling were used to record reference information for the following six forest classes:

1. Conversion - Areas where evidence of anthropogenic change has shifted land use and/or land cover from forest to non-forest conditions (e.g. installation or expansion of urban/residential areas, reservoirs, surface mines, golf courses, ski areas, airports, oil and gas infrastructure, and agriculture areas).

2. Fire - Areas where evidence of fire exists regardless of cause (natural or anthropogenic). Note that post-harvest site preparation fires were recorded but not used in this study. 
3. Harvest - Areas where trees have been mechanically severed and removed and where land use was and remains forest.

4. Stress - Areas where stressors such as insects, disease, drought, and acid rain result in slow canopy degradation leading to leaf area loss and/or tree mortality.

5. Wind - Areas where trees are damaged or killed by hurricanes, tornados, and other severe wind storms.

6. Stable - Areas of established forest which remain spectrally undisturbed throughout the image time series.

Five other types of forest disturbance were also recorded but because the number of observations was too low (e.g. forest altered by debris flows, volcanic activity, flooding, and "other" unknown causes) or because spectral confusion was too high (e.g. initial tests indicated that mechanical treatments such as chaining, brush saw and mastication could not be reliably separated from harvesting) these classes were not included in the RF models. Forest recovery was also recorded, but due to the variably small number of observations at the scene level, we opted to use the VCT output directly, as it reliably captures the distinct pattern (or trend) of increasing spectral greenness which typically follows a pre-time series disturbance (Zhao et al., 2016).

Both the probabilistic and supplemental sampling approaches recorded multiple disturbances per plot, however, we only use the "greatest magnitude" disturbance event (see Table 2), primarily because our disturbance metrics from the Landsat shape-fitting algorithm only captures one change event per pixel. As the greatest magnitude disturbance is one of the most important factors in altering forest structure and carbon storage 
potential (Dale et al., 2001), the presented approach represents a useful mechanism for spatially mapping the locations of potential canopy damage brought on by different forest disturbance agents.

Table 2. The number of probabilistic (P) and supplemental (S) reference samples by agent class for each of the ten Landsat test scenes. Agents shaded in gray were not used in the Random Forest models.

\begin{tabular}{|c|c|c|c|c|c|c|c|c|c|c|c|c|}
\hline \multirow{2}{*}{ East } & \multicolumn{2}{|c|}{ p12r28 } & \multicolumn{2}{|c|}{ p14r32 } & \multicolumn{2}{|c|}{ p16r37 } & \multicolumn{2}{|c|}{ p24r37 } & \multicolumn{2}{|c|}{ p27r27 } & \multicolumn{2}{|c|}{ East Total } \\
\hline & $\mathrm{P}$ & $S$ & $\mathrm{P}$ & $\mathrm{S}$ & $P$ & $S$ & $P$ & $S$ & $\mathrm{P}$ & $S$ & $\mathrm{P}$ & $\mathrm{s}$ \\
\hline Conversion & 0 & 11 & 28 & 13 & 13 & 13 & 5 & 12 & 2 & 18 & 48 & 67 \\
\hline Fire & 0 & 0 & 0 & 31 & 7 & 63 & 0 & 24 & 0 & 20 & 7 & 138 \\
\hline Harvest & 115 & 9 & 19 & 1 & 121 & 7 & 144 & 7 & 74 & 71 & 473 & 95 \\
\hline Stable & 113 & 0 & 164 & 0 & 78 & 0 & 81 & 0 & 150 & 0 & 586 & 0 \\
\hline Stress & 0 & 0 & 2 & 1 & 0 & 0 & 0 & 0 & 1 & 2 & 3 & 3 \\
\hline Wind & 0 & 0 & 0 & 0 & 7 & 31 & 0 & 1 & 0 & 25 & 7 & 57 \\
\hline \begin{tabular}{|l|} 
Sample \\
Total \\
\end{tabular} & 228 & 20 & 211 & 45 & 226 & 114 & 230 & 43 & 226 & 134 & 1,121 & 356 \\
\hline Scene Total & \multicolumn{2}{|c|}{248} & \multicolumn{2}{|c|}{256} & \multicolumn{2}{|c|}{340} & \multicolumn{2}{|c|}{273} & \multicolumn{2}{|c|}{360} & \multicolumn{2}{|c|}{1,477} \\
\hline \multirow{2}{*}{ West } & \multicolumn{2}{|c|}{ p35r32 } & \multicolumn{2}{|c|}{ p36r37 } & \multicolumn{2}{|c|}{ p41r29 } & \multicolumn{2}{|c|}{ p43r33 } & \multicolumn{2}{|c|}{$\mathrm{p} 45 \mathrm{r} 30$} & \multicolumn{2}{|c|}{ West Total } \\
\hline & $\mathrm{P}$ & $\mathrm{S}$ & $\mathrm{P}$ & $\mathrm{S}$ & $\mathrm{P}$ & $\mathrm{S}$ & $P$ & $S$ & $\mathrm{P}$ & $S$ & $\mathrm{P}$ & $\mathrm{s}$ \\
\hline Conversion & 0 & 14 & 2 & 11 & 0 & 13 & 2 & 11 & 0 & 16 & 4 & 65 \\
\hline Fire & 25 & 58 & 46 & 50 & 106 & 55 & 20 & 157 & 31 & 19 & 228 & 339 \\
\hline Harvest & 14 & 19 & 1 & 2 & 7 & 49 & 81 & 185 & 82 & 4 & 185 & 259 \\
\hline Stable & 114 & 8 & 163 & 0 & 82 & 0 & 116 & 0 & 99 & 0 & 574 & 8 \\
\hline Stress & 77 & 14 & 16 & 0 & 34 & 2 & 4 & 0 & 2 & 2 & 133 & 18 \\
\hline Wind & 0 & 0 & 0 & 0 & 0 & 0 & 0 & 0 & 0 & 0 & 0 & 0 \\
\hline \begin{tabular}{|l|} 
Sample \\
Total \\
\end{tabular} & 230 & 113 & 227 & 61 & 229 & 119 & 219 & 353 & 212 & 39 & 1,117 & 685 \\
\hline Scene Total & \multicolumn{2}{|c|}{343} & \multicolumn{2}{|c|}{288} & \multicolumn{2}{|c|}{348} & \multicolumn{2}{|c|}{572} & \multicolumn{2}{|c|}{251} & \multicolumn{2}{|c|}{1,802} \\
\hline
\end{tabular}

\subsubsection{Landsat time series}

Four processing steps were used to produce the annual image stacks for the ten Landsat scenes used in this study. First, near cloud free images falling within the peak growing season window (i.e. June-September) were selected from the Landsat Thematic Mapper (TM) and Enhanced Thematic Mapper (ETM+) satellite records (see Huang et al., 2009 for more details). Second, the Landsat Ecosystem Disturbance Adaptive Processing System 
(LEDAPS, Masek et al, 2006) was used to atmospherically correct the images and convert them from digital numbers to earth surface reflectance. Third, a cloud clearing algorithm (see Schleeweis et al., in press) was used to replace anomalous pixels (e.g. cloud, shadow, scan line corrector drop out) with clear observations from other peak growing season images collected from within the same year (Huang et al., 2010b). After these initial steps some of the scenes still had years with unacceptable amounts of obscured pixels, thus the number of images comprising each of the ten stacks varied from a low of 23 to a maximum of 27 (Table 3). The fourth step involved calculating three spectral vegetation indices including the Forestness Index (FI, Huang et al., 2008; 2009), the Normalized Burn Ratio (NBR, Key and Benson, 2005), and the Normalized Difference Vegetation Index (NDVI, Rouse et al., 1973). To ensure the spectral data and vegetation indices responded to disturbance in the same numerical direction the NBR and NDVI images were multiplied by 1 , followed by the addition of a constant value large enough to prevent negative numbers. After processing, trajectories of Landsat B5 and the three vegetation indices (FI, NBR and NDVI) were individually used in the shape-fitting algorithm to derive pixel-level change metrics for use as predictor variables in our causal agent models.

\subsubsection{Shape-fitting metrics}

Adapted from the nonparametric statistical literature (Meyer, 2008; Meyer et al., 2013) the shape-fitting algorithm (Moisen et al., 2016) is based on the assumption that the trend in each pixels spectral trajectory is "smooth", and that a simple quadratic regression spline can be used to estimate these trends. The key difference in this approach is that to avoid 
over-fitting the often noisy spectral signal, the spline functions were constrained to adhere to six predefined "shape" patterns, which were identified according to known responses of

Table 3. The date range and number of images in each test scene's Landsat time series.

\begin{tabular}{|c|c|l|}
\hline Year & \# Images & \multicolumn{1}{|c|}{ Date Range } \\
\hline p12r28 & 24 & $1985,1987-1991,1993-2010$ \\
p14r32 & 27 & $1984-2010$ \\
p16r37 & 26 & $1984,1986-2010$ \\
p24r37 & 25 & $1986-2010$ \\
p27r27 & 23 & $1986-1988,1990-1997,1999-2010$ \\
p32r35 & 26 & $1984,1986-2010$ \\
p36r37 & 26 & $1984,1986-2010$ \\
p41r29 & 26 & $1985-2010$ \\
p43r33 & 27 & $1984-2010$ \\
p45r30 & 26 & $1985-2010$ \\
\hline
\end{tabular}

the chosen spectral bands/vegetation indices to a range of natural and anthropogenic disturbance agents (e.g. see Kennedy et al., 2007 Figure 3). The six shape types used in this study (and the ecological behavior ascribed to each) are defined as follows (see Figure 2 for graphical examples):

1. Flat - indicates a forest in stable condition.

2. Decreasing - indicates a young forest which is accumulating leaf area and/or biomass, potentially in a state of recovery from a past disturbance which occurred prior to the beginning of the image time series.

3. Jump - captures short duration, abrupt changes in forest structure or canopy cover typically resulting from harvests or wildfires. 
4. Vee - indicative of recovering or stable forests which begin to experience a gradual loss of leaf area or increasing tree mortality such is common with insect, disease and drought damage.

5. Inverted Vee -represents forests which begin the time series as stable but then begin a gradual decline in leaf area or structure followed by a gradual period of recovery.

6. Increasing - this linear shape reflects forests which are experiencing long, gradual declines in leaf area and/or canopy structure often resulting from slow acting disturbances which occur early (or before) the beginning of the time series.
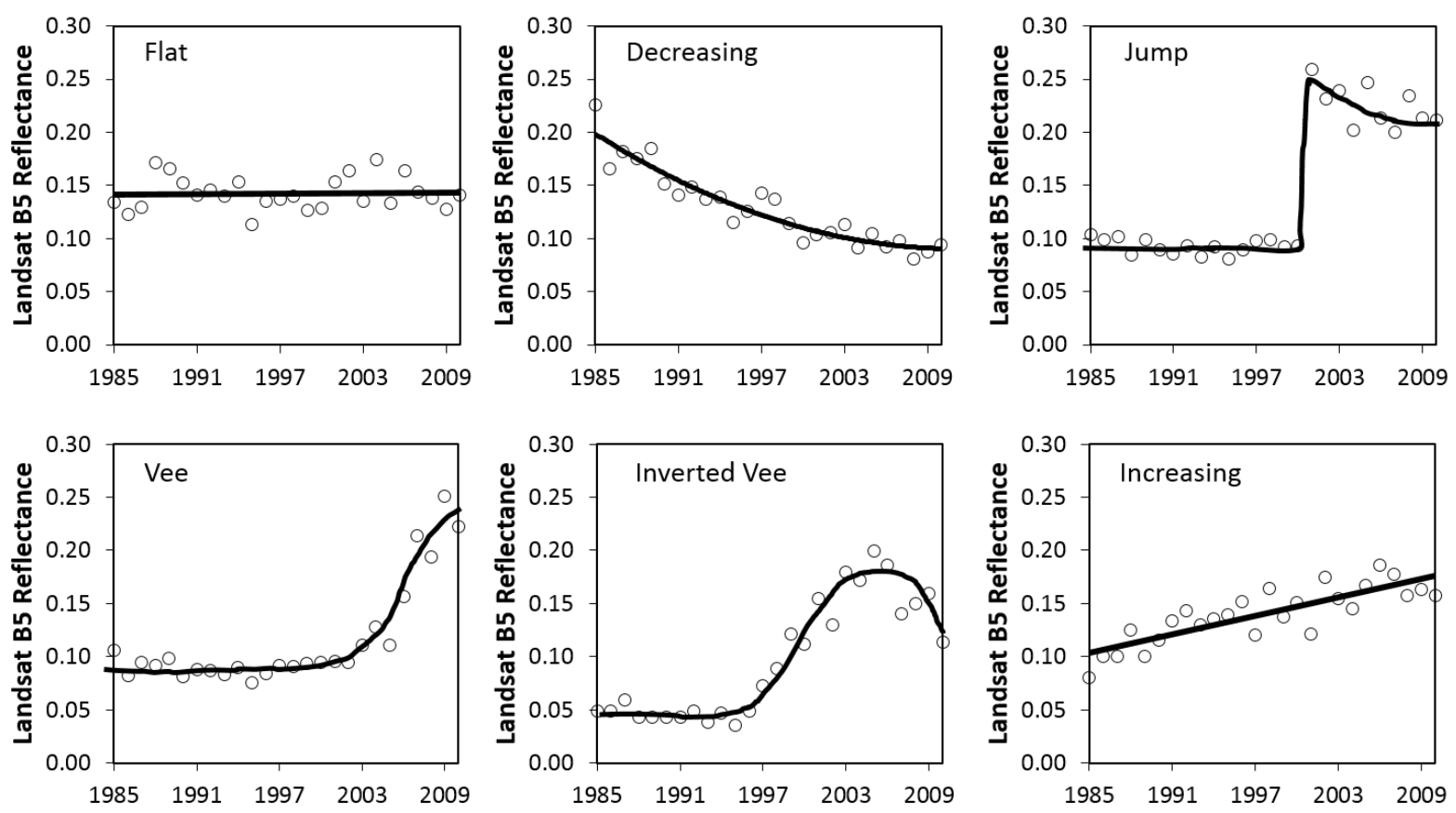

Figure 2. The six pre-defined "shape" patterns used in the shape-fitting algorithm. Shapes depict known spectral patterns caused by disturbance agents and mature undisturbed forests. Although examples are shown in units of Landsat band 5 reflectance, the algorithm was also run on FI, NBR and NDVI. 
The R statistical package "ShapeSelectForest" (Meyer et al., 2015), freely available on the Comprehensive R Archival Network (or CRAN), was used to fit all six of the constrained spline shapes to every forest pixel identified by VCT. For each of the four spectral trajectories used, the shape with the lowest sum of squares error (including a penalty for complexity based on the number of degrees of freedom from the model fits) was selected as the "best" shape. Because of random error (i.e. outliers due to atmospheric attenuation and noise) and differences in spectral response, the pixel-level shapes selected for each band/index were often different. After determining the best shape fits, metrics describing the trajectory pattern were also calculated for every pixel. These included the year of detected change (which is used in step two of our modeling process to assign timing of disturbance), two measures of magnitude (i.e. absolute and relative spectral change), duration (i.e. the number of years or image intervals the detected spectral change lasted for), and the annual rates of growth and recovery following a detected spectral change (i.e. slope of spectral trend). Because the vee and inverted vee shapes are non-linear, the change point denoted as an upward trend in the model often occurred prior to the actual event in the forest canopy. To account for this lag we adjusted the change points for these shapes to better reflect the point where the spectral response begins to accelerate in the upward direction (e.g. see stress signatures, Schroeder et al., 2014 Figure 6f). Overall, the shape-fitting process yielded 24 disturbance metrics, which were used to predict causal agent groups in RF and 4 metrics which were used in the rule-based model to assign disturbance timing. For more details on the constrained spline fitting procedure, including computational notation and use of degrees of freedom constraints see Meyer et al. (2013) and Moisen et al. (2016). 


\subsubsection{Additional predictor variables}

Several other spatial datasets were also used as model predictor variables. To account for topographic effects we included elevation (30 m resolution National Elevation Dataset or NED), and derived variables including slope (in degrees) and cosine/sine transformed aspect (Beers et al., 1966). Coarse resolution maps of forest probability of occurrence (Blackard et al., 2008) and forest types (Ruefenacht et al., 2008) derived from $250 \mathrm{~m}$ MODIS imagery (downscaled to $30 \mathrm{~m}$ ) were included to help account for broad scale differences in species disturbance dynamics. We downloaded and rasterized the vectorbased fire burn perimeters from MTBS (Eidenshink et al., 2007) and developed a cumulative presence-absence layer for fires occurring between 1984 and 2010. When used as a predictor, this $30 \mathrm{~m}$ fire perimeter mask still allowed smaller fires to be predicted outside, and unburned areas to be predicted inside, the MTBS burn perimeters. Similarly, we used two 30 m cumulative presence-absence masks of forest disturbance, using the VCT annual disturbance maps (1984-2010, Huang et al., 2010a) and the annual global forest change product (2000-2010, Hansen et al., 2010). Finally, to take advantage of geometric patterns of different disturbance types (e.g. harvests tend to be smaller and geometrically shaped compared to fires which are often larger and irregularly shaped) we used a 3x3 moving window segmentation algorithm to group VCT pixels that were disturbed in the same year into discrete patches. For each of these derived disturbance patches we calculated geometry metrics, including area, perimeter, fractal dimension, and shape index (see p. 88-108 in McGarigal et al., 2012). For a complete list of all 37 predictor variables see Electronic Supplement, Table S1. 
2.3. Mapping disturbance agents and undisturbed forest classes

\subsubsection{Step 1: Empirical modeling of causal agents and stable forest}

The first step of our two-step modeling approach involved building temporally indifferent Random Forest (RF, Breiman, 2001) models to empirically predict the presence of five disturbance agents (conversion, fire, harvest, stress, wind) and stable (i.e. undisturbed) forest. Models were built individually for each of the 10 Landsat scenes using the $\mathrm{R}$ statistical package ModelMap (Freeman et al., 2014) available on the Comprehensive R Archive Network (or CRAN). ModelMap offers a simplified interface for creating complex RF models explicitly for spatial map production. To facilitate the needs of our study, ModelMap was updated with several new features including the ability to simultaneously model multi-categorical response variables. Models were constructed using the default setting of 500 trees per forest, while the number of predictor variables used to determine the node splits in each tree was set to six (i.e. the square root of the total number of predictor variables). Since there is no accuracy penalty in RF for using correlated variables we opted to use all 37 predictors despite varying levels of observed correlation (note most correlation occurred among variables within each of the five predictor groups). Although correlated predictor variables complicate analysis of variable importance we do use a rank scoring system based on the RF mean decrease in accuracy metric to explore the "relative" importance of the five predictor groups (see section 2.6). Because the scene-specific response data were in most cases highly imbalanced (i.e. one or more agent classes were significantly more prevalent than the others) a down sampling approach (e.g. see Freeman et al., 2012; Mellor et al., 2015) was used to compensate for RF's tendency to predict more 
prevalent response classes (Weiss \& Provost, 2003). This involved systematically reducing the number of observations of the most prevalent classes, while still maintaining the same relative proportion of all classes observed in each scene. Since the down sampled observations were selected at random for each of the 500 trees generated in RF, all of the reference data were eventually used to train the models. To create the agent maps, we applied the RF models to the spatial predictor layers using the raster package (via ModelMap) in R.

\subsubsection{Step 2: Rule-based assignment of disturbance year}

The second step of our modeling approach involved assigning a year, duration and magnitude to the empirically predicted disturbances identified in step one. Using the flat2parameter function in ShapeSelectForest a series of decision rules were applied to the shape number, year, magnitude and duration outputs from the shape fitting algorithm (described above in section 2.2.3.). The first two rules assigned pixels with no disturbance a year, a duration and a magnitude of zero. These included both pixels predicted as stable in the agent map, as well as pixels which had flat or decreasing shapes in all four spectral bands. In the event that RF predicted a disturbance, but all four spectral inputs yielded flat or decreasing shapes, the agent map was recoded to stable forest (note less than $0.12 \%$ of pixels were impacted across the ten scenes). The third rule assigned pixels predicted as stress the median year, duration and magnitude of all the shapes that were not labeled flat or decreasing. Lastly, the fourth rule assigned year, duration and magnitude to all other disturbance classes. Since these disturbances occurred abruptly in the temporal domain we took the median from only the jump shapes if possible. If none of the remaining shape 
outputs were jumps, the median was derived using the vee, inverted vee and increasing shape types.

\subsection{Quality assessment of causal agent and stable forest models}

To evaluate the quality of the temporally indifferent causal agent models, the out of bag (OOB) predictions from each scene's RF model were used to derive various measures of agreement for the disturbance and stable forest classes. Because the OOB observations are not used for model training, these estimates are essentially cross-validated accuracy estimates (Cutler et al., 2007). Due to the limited number of probabilistically collected reference samples we use all the OOB predictions from the reference data, including both the probabilistic and purposively sampled plots to assess "model quality". Since this assessment is based on a non-probabilistic sample we are not constructing estimates for inference. Rather, we are reporting the metrics on how well the model predicted over the "population" of training plots, each one excluded from the model-fitting through the OOB

process. For the disturbance agents, overall agreement was derived in three different ways. The first way required both the causal agent to be correct and the disturbance year to be assigned within \pm 1 year of the reference date, while the other two ways required only the agent or year to be correct but not the other. In addition, the OOB commission and omission errors are presented graphically to help visualize geographic differences across the diverse set of Landsat scenes. Lastly, the causal agent OOB predictions were generalized to the disturbed/not disturbed (DND) level and compared with output from binary RF models specifically trained to predict DND classes. The binary models were setup using the same RF parameters (e.g. number of trees, node splitting rules) and predictor 
variables used for the multiclass agent models described above in step one (see section 2.3.1.).

\subsection{Quality assessment of forest disturbance year model}

To assess the quality of the disturbance year model (applied in step two) we plotted frequency histograms which show the percentage of disturbed plots that fall within different time intervals of the reference data. These plots of observed minus predicted disturbance year are plotted into 11 bins (ranging from -20 to +20 years) for each of the five agent classes, as well as for all disturbances grouped across the entire data set. These yearly comparisons are based solely on the 1,639 disturbance plots that were modeled correctly by RF (i.e. diagonal columns in the agreement matrices shown in Electronic Supplement, Table S2).

\subsection{Predictor variable importance}

To help gauge the relative importance of the various predictor variables we took the mean decrease in accuracy, which is a measure of how much more helpful than random a particular variable is at classifying the data, and assigned the top ten predictors in each scene a score of 1 (assigned to the $10^{\text {th }}$ most important variable) to 10 (assigned to the most important variable). These relative ranking scores were then summed across the test scenes and plotted graphically to help assess the importance of the five predictor variable groups (spectral metrics, patch geometry, forest occurrence, disturbance and topography) used in the RF models. To avoid issues with correlated variables focus was placed on analyzing the broader contributions of the suite of variables in each group. 
2.7. Spatial and temporal patterns of forest disturbance agents

A series of maps and figures are presented to highlight the spatial and temporal patterns of disturbance resolved by our two-step modeling approach. For each of the test scenes, annual rates of disturbance (derived as the area of disturbed forest divided by total forest area) are plotted for the period 1985-2009 (note the first and last years were modeled less accurately so are omitted for clarity). Prior to calculating disturbance rates, the area mapped for each agent class was adjusted for error using the probabilistic sample plots (e.g. see Olofsson et al., 2014). Because the disturbance agents were originally modeled in a temporally indifferent fashion, the adjusted area was spread evenly across the years of each scenes image time series. Due to the limited number of samples only the agent classes with 5 or more probabilistic samples were adjusted for error (see Table 2).

\section{Results}

3.1. Quality assessment of causal agent and stable forest models

\subsubsection{Overall agreement}

Using the OOB predictions from RF three measures of overall agreement (1. agent \& year \pm 1 , 2. agent only, and 3. year \pm 1 only) were derived for the ten Landsat test scenes (Figure

3). The results showed that agreement was highest when only causal agent was considered (avg $=80 \%, \min =69 \%, \max =86 \%$ ), and was lowest when both agent and year (within \pm 1 of the reference date) were required to be correct ( $\operatorname{avg}=71 \%, \min =56 \%, \max =80 \%$ ). Only two scenes (p14r32 and p43r33) had the highest agreement at the year \pm 1 only level, 
suggesting that in most cases, timing of disturbance was more difficult to assign then disturbance causality.

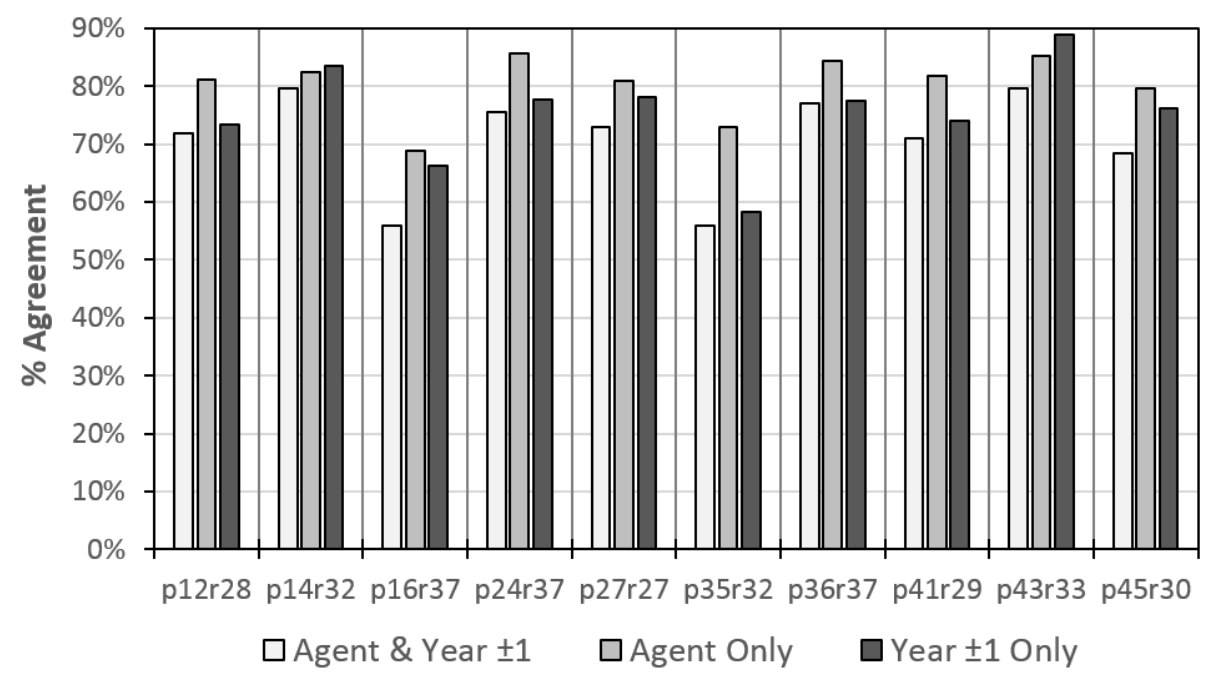

Figure 3. Three levels of overall agreement derived using the out of bag (OOB) predictions from each test scenes Random Forest model.

\subsubsection{Model errors}

Taken from each scenes agreement matrix (Electronic Supplement, Table S2), the omission and commission errors showed that fire and stable forest were consistently modeled well across all the test scenes. In fact, of the five disturbance agents tested, the fire class had the lowest error rates, which were on average less than 15\% (Figure 4). The stable forest class also performed well, with an average across scene error rate of only 18\% (Figure 4). Although the model errors for fire and stable forest were fairly well balanced (i.e. omission and commission were generally within $\pm 5 \%$ of one another) there was a slight tendency for disturbance to be confused with stable forest. The remaining disturbance classes had 

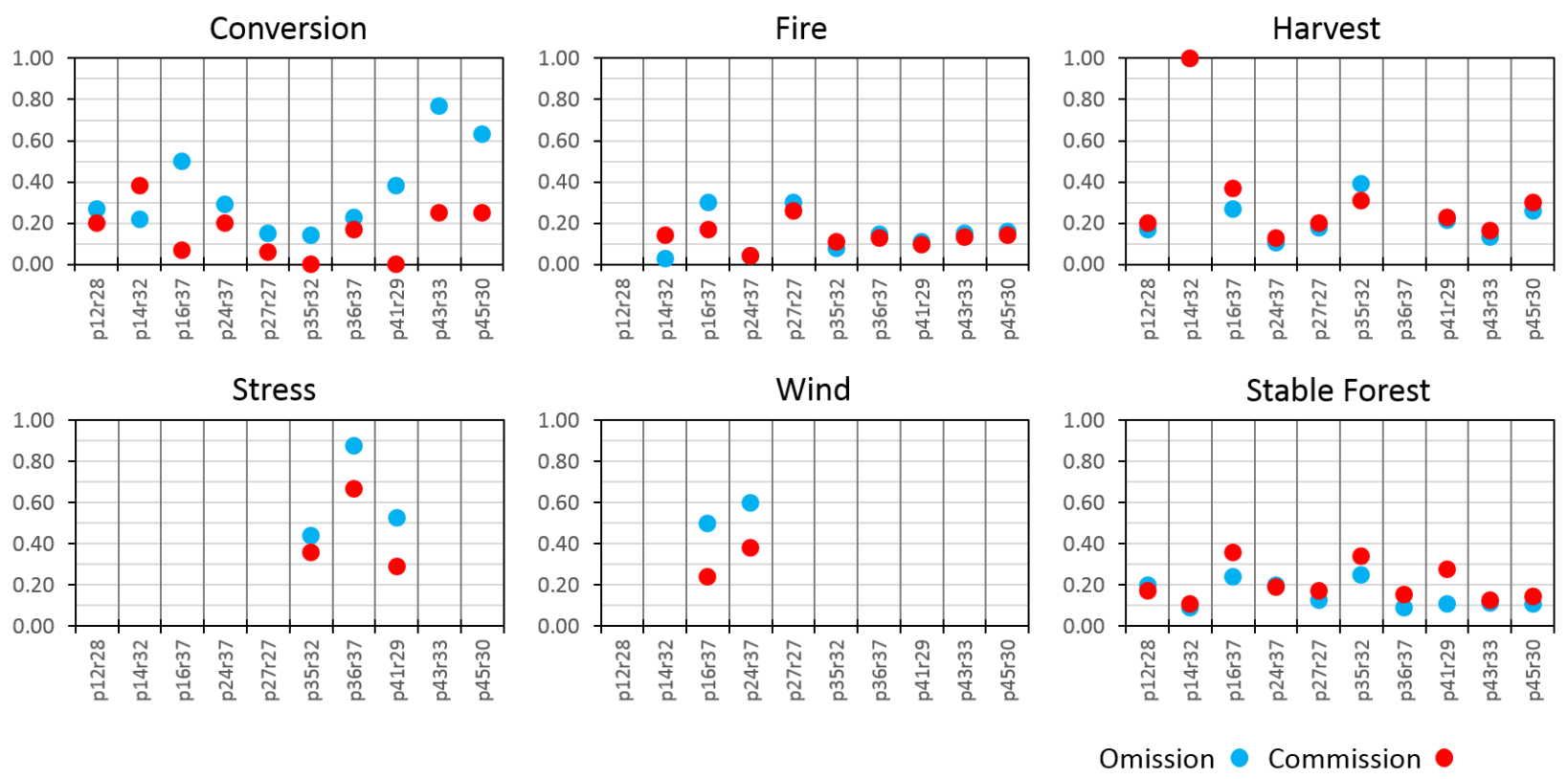

Figure 4. Model-based errors of omission and commission for the five disturbance agents and stable forest.

average to low accuracies. For example, although the harvest class yielded less than $25 \%$ error for more than half of the nine test scenes, two scenes (p16r37 and p35r32) had error rates approaching $40 \%$, and one scene (p14r32) had 100\% error (Figure 4). The conversion class also yielded highly variable results, with error rates ranging anywhere from $0 \%$ to $77 \%$. Additionally, the model errors for conversion were generally not well balanced, especially in three of the western scenes (p41r29, p43r33, and p45r30 Figure 4). Stress and wind were both modeled rather poorly with error rates ranging from $29 \%$ to $88 \%$ and $24 \%$ to $60 \%$, respectively. On average, omission rates for stress and wind were $20 \%$ higher than errors of commission. 


\subsubsection{Binary disturbance comparison}

To determine if any disturbance information was lost by modeling causality directly we compared the results from the agent models (summarized to the DND level) with the output from RF models specifically trained to predict binary disturbance. Overall agreement and kappa results showed that the causal agent models were equally, or slightly more accurate than the simpler binary disturbance models (Table 4). In fact, the generalized causal agent models had slightly higher overall agreement in five of the scenes and higher kappa in six of the scenes. Interestingly, most of these scenes with higher agreement (three out of five) and kappa (four out of six) were located in the eastern region. Only one test scene (p41r29) had slightly better results for the binary disturbance model.

Table 4. Overall agreement and kappa for binary disturbance models and for causal agent models generalized to the disturbed/not disturbed (DND) level. Models with the highest accuracy are denoted in bold italic.

\begin{tabular}{|c|c|c|c|c|}
\hline & \multicolumn{2}{|c|}{ Overall Agreement } & \multicolumn{2}{c|}{ Kappa } \\
\hline Scene & $\begin{array}{c}\text { Binary DND } \\
\text { Model }\end{array}$ & $\begin{array}{c}\text { Causal Agent } \\
\text { Model - DND }\end{array}$ & $\begin{array}{c}\text { Binary DND } \\
\text { Model }\end{array}$ & $\begin{array}{c}\text { Causal Agent } \\
\text { Model - DND }\end{array}$ \\
\hline p12r28 & 0.83 & 0.83 & 0.66 & 0.66 \\
p14r32 & 0.85 & 0.87 & 0.67 & 0.72 \\
p16r37 & 0.85 & 0.85 & 0.58 & 0.59 \\
p24r37 & 0.87 & $\mathbf{0 . 8 9}$ & 0.68 & 0.73 \\
p27r27 & 0.86 & $\mathbf{0 . 8 7}$ & 0.71 & 0.74 \\
\hline p32r35 & 0.73 & $\mathbf{0 . 7 8}$ & 0.40 & 0.52 \\
p36r37 & 0.85 & 0.85 & 0.70 & 0.70 \\
p41r29 & 0.91 & 0.89 & 0.75 & 0.73 \\
p43r33 & 0.95 & 0.95 & 0.85 & 0.85 \\
p45r30 & 0.89 & 0.90 & 0.77 & 0.78 \\
\hline
\end{tabular}

\subsection{Disturbance year model errors}


Frequency histograms showing the distribution of observed minus predicted disturbance year for each of the five agent classes (Figure 5a) showed that fire had the most accurate year assignment, with $78 \%$ of its disturbances assigned the correct year by our model. The harvest and conversion classes also had relatively high percentages with $69 \%$ and $53 \%$ of its disturbance assigned the correct year, respectively. The fire, harvest and conversion
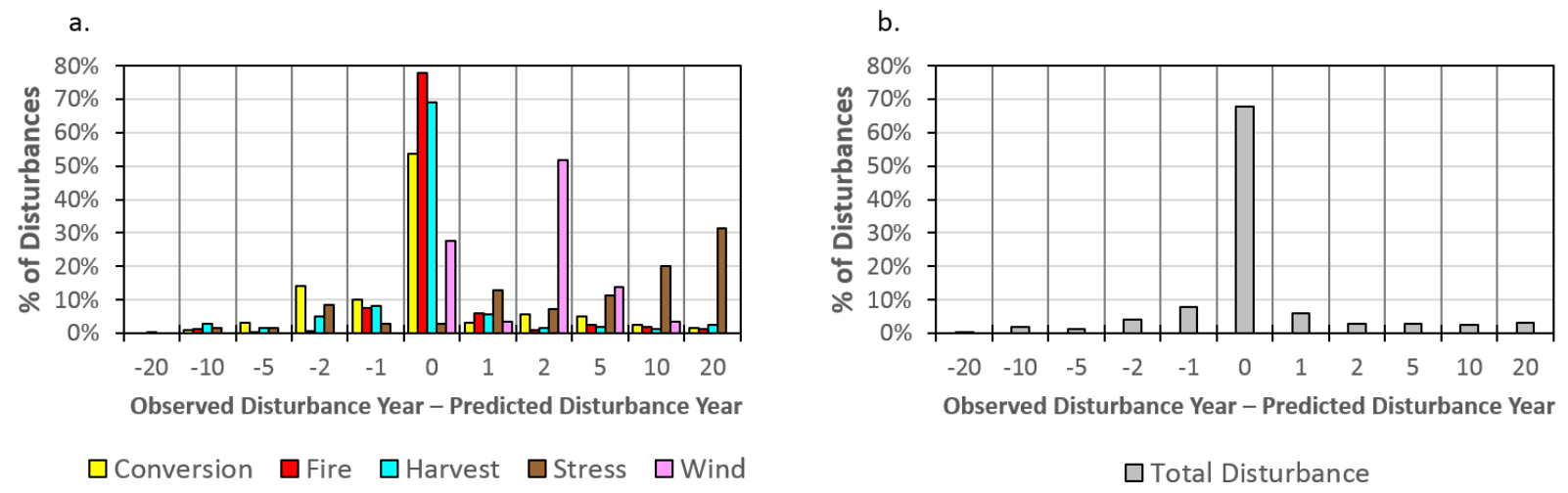

Figure $5 \mathrm{a}$ and $\mathrm{b}$. Frequency histograms showing the observed (from the reference data) minus predicted (from the rule-based model) year of disturbance plotted as a percentage of a.) each agent class, and b.) total disturbance from across the ten Landsat test scenes. Note only the correctly classified disturbance plots from step one $(n=1,639)$ are used in these graphs.

classes also had fairly well balanced errors, as most disturbances were only off by \pm 2 years of the reference date. On the other hand, the years assigned to stress and wind were much less accurate, with only $3 \%$ and $28 \%$ of their respective disturbances assigned the correct year by our model. Errors for stress and wind were also heavily skewed, such that most years were considerably under estimated. Although $72 \%$ of the wind disturbances had their disturbance years under assigned, the vast majority (55\%) were only off by two years. 
In contrast, $83 \%$ of the stress disturbances were under assigned, however $20 \%$ of these were off by 10 years, and $31 \%$ were off by 20 or more years.

Despite the fact our rule-based model consistently under estimated the disturbance year for two of the five agent classes, the impact across the entire dataset was much less significant given the low overall number of wind and stress disturbances compared to the other agent types (Table 2). For example, Figure $5 b$ shows the distribution of observed minus predicted disturbance year with the histogram computed as a percentage of total disturbance from all ten test scenes $(n=1,639)$. Since wind $(n=29)$ and stress $(n=70)$ only make up roughly $6 \%$ of the total observations, nearly $70 \%$ of all correctly classified disturbances were assigned the right year by our model. Also, across the entire data set the errors are low and normally distributed, such that most of the disturbances (88\%) fall within \pm 2 years of the reference date.

\subsection{Predictor variable importance}

Since RF splits predictor importance equally among highly correlated variables (Freeman et al., 2015) we opted to group the 37 individual predictors into five broader classes (e.g. spectral metrics, patch geometry, forest occurrence, disturbance and topography, Electronic Supplement, Table S1). By constraining most of the importance splitting to variables within the same group (e.g. see correlation plots, Electronic Supplement, Figure S2), we were able to more generally evaluate which variable groups were most useful for predicting forest disturbance agents. Based on RF mean decrease in accuracy, 21 variables had at least one scene where they were among the top ten most important predictors. In 
addition, these 21 predictors included variables from all five general predictor groups (i.e. spectral metrics, patch geometry, forest occurrence, disturbance and topography). The importance value rank scores (Figure 6) show that across all ten test scenes MTBS was, in a relative sense, the most important predictor variable. With a rank score of 50 in the west and 33 in the east, MTBS was the most important predictor in all five western test scenes, and in 3 out of 4 eastern test scenes. The spectral metrics were the next most important

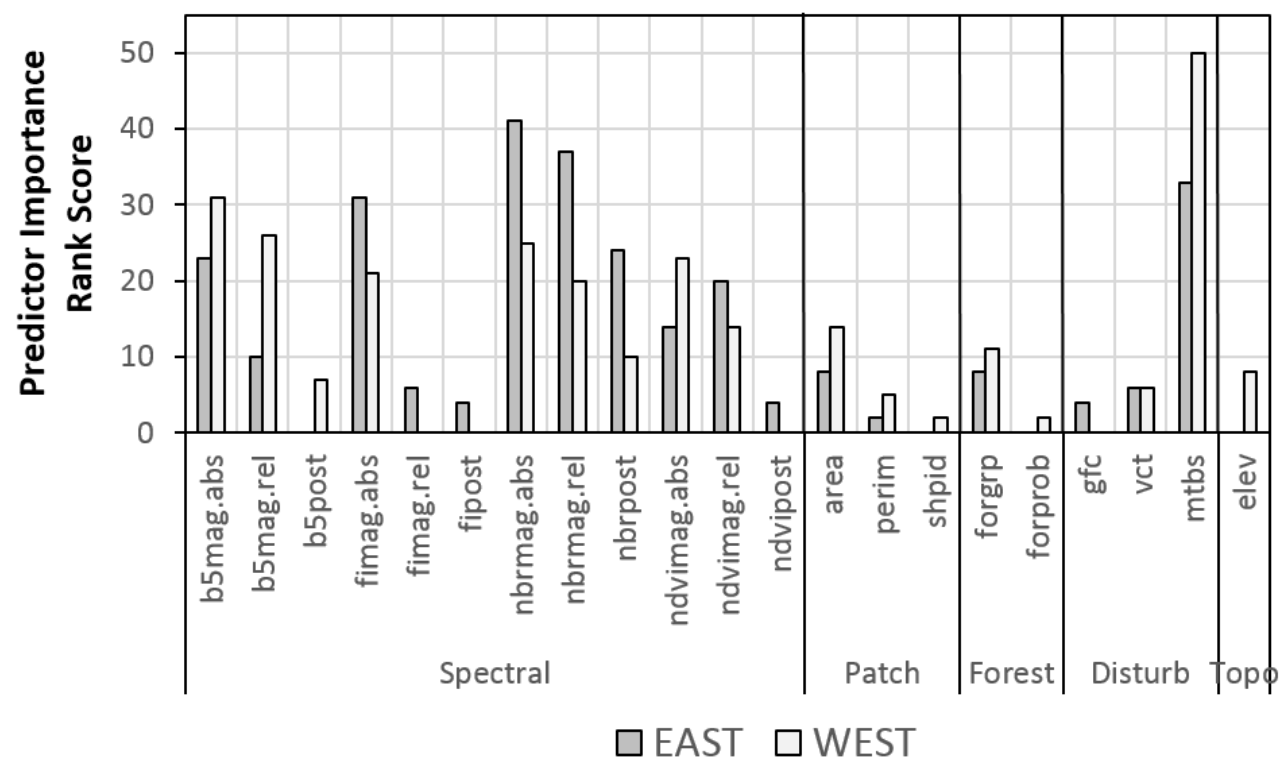

Figure 6. Predictor variable importance rank scores derived using the mean decrease in accuracy metrics from the ten scene-level Random Forest models. Scene-level rank scores are summarized by the east and west regions described in Table 1. A description of the predictor variables (x-axis) can be found in the Electronic Supplement, Table S1.

group of predictors, with four individual variables having rank scores greater than 30 . All of the highest ranking spectral metrics were some form of change magnitude (see b5mag.abs, fimag.abs, nbrmag.abs, and nbrmag.rel, Figure 6). The only other spectral metrics to achieve a top ten ranking were the post disturbance recovery rates, although except for NBR post rate in the east region (rank score $=24$ ), most of these were minimally 
impactful (i.e. had low rank scores in only one or two scenes). Although the area and perimeter variables from the patch geometry group were found to be important in several of the scene models ( 7 and 4, respectively), both tended to fall toward the lower end of the importance scale (average across scene importance $<3$ ). Conversely, the forest occurrence group was generally unimportant at the region level (rank score east $=8$ and west $=11$ ), however it was the third most important variable in two of the three scenes were it made the top ten list (p14r32 and $\mathrm{p} 35 \mathrm{r} 32$ ). The only variable in the topography group to make the top ten list was elevation, where it was found moderately important (rank score $=4$ ) in two of the western test scenes (p35r32 and p36r37).

\subsection{Spatiotemporal patterns of forest disturbance agents}

\subsubsection{Annual disturbance rates}

The agent and year maps were combined to derive annual rates of disturbance for each of the ten Landsat test scenes. Computed as the yearly percentage of forest area impacted by the five disturbance agents, these rates (shown in Figures 7a-e) were highly variable across space and time. For example, although conversion and wind (Figures 7a and e) both had equally low average across scene rates of disturbance $(0.08 \% / \mathrm{yr})$, the patterns of conversion were persistently low (i.e. all $<0.60 \% / y r$ ) and relatively steady across time, whereas wind had rates near 0\% for all years except for one large event in 1990 which exceeded 3\%/yr. The next highest average across scene rates of disturbance were fire and stress $(0.33 \% / y r$ and $0.74 \% / y r$, respectively), both of which had temporal patterns defined by large episodic events. Not surprisingly, the scenes in the eastern region had much lower annual rates of fire (maximum of $0.45 \%$ ) than those in the western region (maximum of 
10.29\%). Unlike fire, which mostly had rates hover near $0 \%$ except for large fire years, stress remained relatively consistent (i.e. $0.50 \%-1.00 \% / y r$ ) except for three distinct peaks in 1991, 1995, and 2007. Lastly, with an average across scene rate of 1.07\%/yr the harvest class (Figure 7c) had the highest overall rates through time. Despite three scenes which had very low rates across the entire study period (e.g. p14r32, p35r32, and p41r29 never exceeded $0.60 \% / y r$ ) most hovered around 1.00\%-2.00\%/yr. Notable exceptions were the large peak in p16r37 which reached a high of $6.00 \% / y r$ in 1990 , and the distinct trends of increasing rates in p24r37 between 1992 (1.14\%/yr) and 2000 (4.75\%/yr) and in p45r30 between 1986 (0.65\%/yr) and 1991 (3.75\%/yr). Overall, the average annual rate of harvesting was nearly three times higher in the eastern test scenes.

\subsubsection{Spatial predictions of causal agents}

Maps of forest disturbance agents and stable forest are shown for each of the ten Landsat test scenes (see Electronic Supplement, Figure S1) and for select geographic subsets, which highlight various successes of the employed mapping approach (Figure 8a-h). Maps of conversion show that forest area was lost to a number of different anthropogenic activities such as residential development (Figure 8d) and open pit mining (Figure 8e). Fires were well resolved resulting in high levels of spatial and temporal agreement with MTBS (Figure 8c). Harvest maps were able to separate forest management activities from land use conversion (Figure 8a), as well as resolve differences in land owner response to federal land management policy (discussed below). Although our model predictions for stress and 


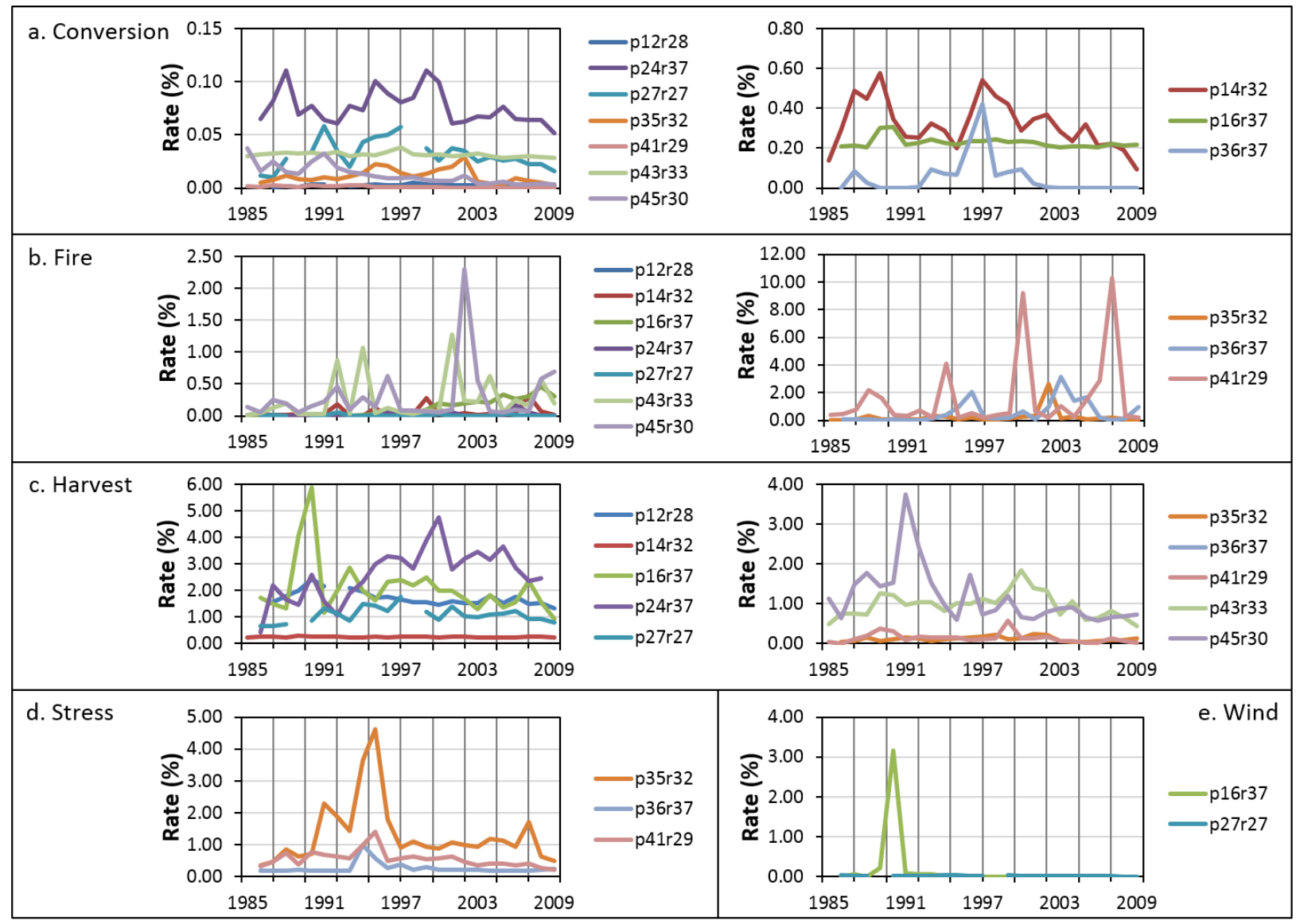

Figure 7a-e. Annual rates of a.) Conversion, b.) Fire, c.) Harvest, d.) Stress, and e.) Wind predicted for each of the ten Landsat test scenes.

wind were not overly accurate at the pixel-scale the maps produced for these agents still yielded realistic predictions which agreed well with other published data sets. For example, model predations for stress were well aligned with the boundaries of cumulative mortality (1991-2010) derived from the U.S. Forest Service, insect detection survey (IDS) maps (Figure 8b). Similarly wind, which was only observed in p16r37 along the Atlantic coast of South Carolina, was found to be in relatively good agreement with a previously published map depicting the impacts of Hurricane Hugo (see Rittenhouse et al., 2010, Figure 8f). 


\section{Discussion}

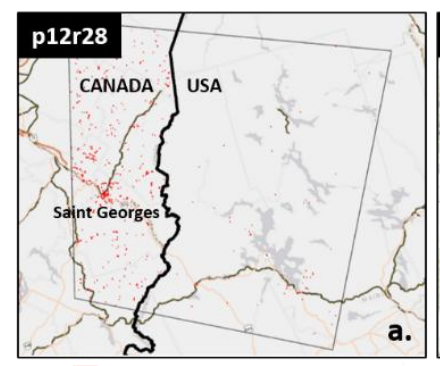

$\square$ Conversion $\quad{ }^{20} \quad 40$

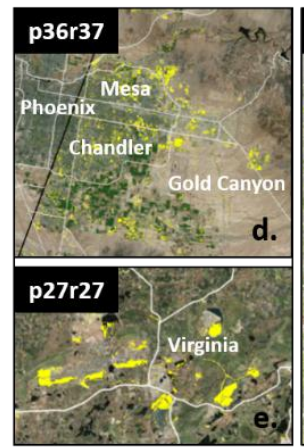

Conversion $\begin{array}{ccc}0 & 11 \\ 1 & 1 & 1 \\ 1 & & 1\end{array}$

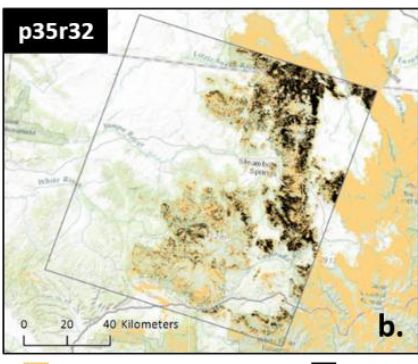

IDS Mortality (1991-2010) Stress

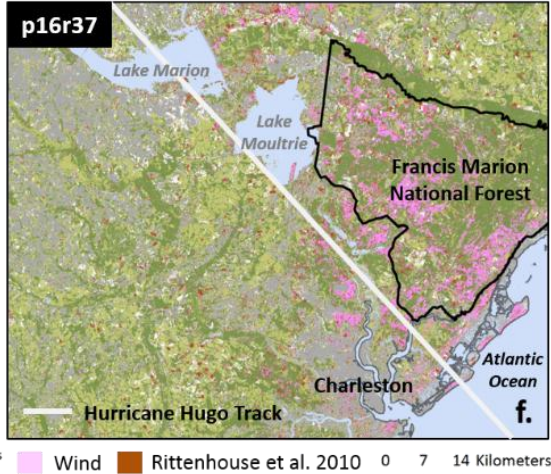

f.
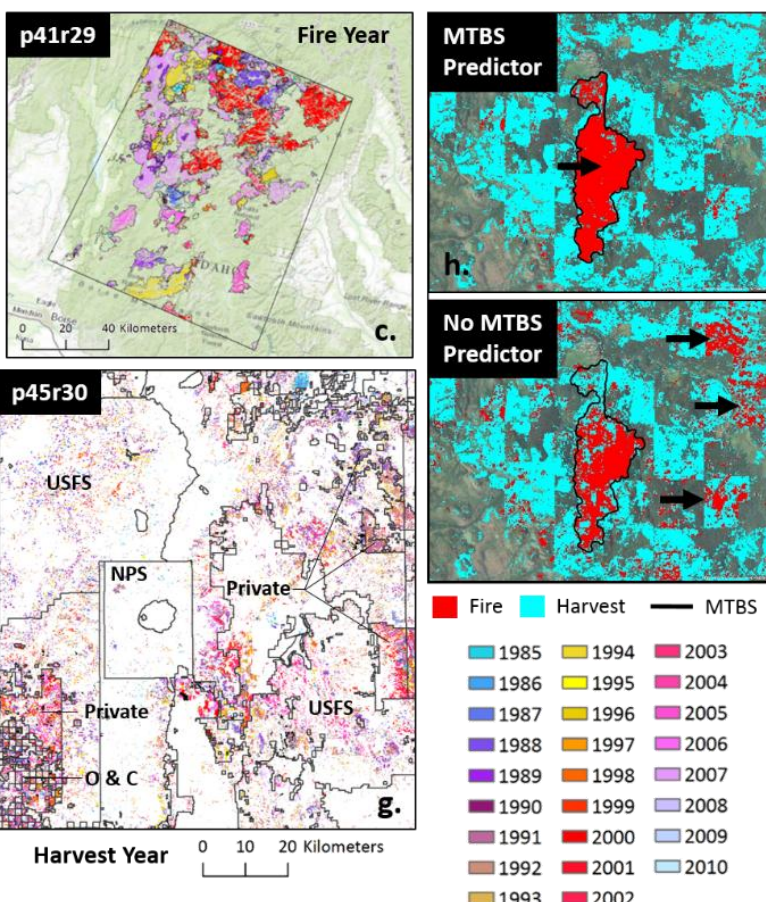

Figure 8a-h. Examples of forest disturbance causal agent maps showing a.) Conversion along the Canadian border, b.) Stress in the Rocky Mountains, CO c.) Fires in central ID d.) Conversion in Phoenix, AZ, e.) Conversion in central MN, f.) Wind damage in SC and g.) Harvests in central OR. Inset h. highlights the spatial impact of using MTBS as a predictor variable in Random Forest.

\subsection{Causal agent and stable forest model quality}

In general, the developed causal agent models performed well, as eight out of the ten Landsat test scenes had overall agreement greater than $80 \%$ (see agent only results, Figure 3). Not surprisingly, the two scenes with the greatest abundance of subtler, more difficult to classify disturbances (i.e. p16r37 wind and p35r32 stress) also had the two lowest levels of overall agreement (69\% and 73\%, respectively). Although two scenes had higher agreement at the year only level, most of the models performed better when only the agent 
class was considered (Figure 3). Requiring both the agent and year to be assigned correctly yielded overall agreements that were on average $10 \%$ lower than those at the agent only level. Based on the performance of our disturbance year model (discussed below) this discrepancy could likely be negated simply by increasing the temporal window of acceptability to \pm 2 years. Although requiring disturbance year to be within \pm 1 year of the reference date is a commonly applied threshold used to account for gaps in image acquisition, the temporal window of acceptability can be modified to adjust accuracy to meet the needs of different users.

At the agent class level, errors of omission and commission (Figure 4) indicate that fire and stable forest were consistently modeled well across all of the test scenes. Other agents however performed more variably. Our ability to predict agent classes such as conversion, stress and wind, which had some of the highest error rates, was undoubtedly compromised by a lack of reference data. In fact, without the addition of the supplemental data (described above in section 2.2.1.) several of the agents would not have had enough data to include in our analysis (e.g. most of the wind data in p16r37 came from FIA plots). Another positive result was classes with the largest errors, nearly all had higher rates of omission (Figure 4), thus prediction levels were conservative, which is typically preferred to the converse where too many pixels are incorrectly classified into one particular class. Furthermore, most of the classification error arose due to confusion between different agent classes (see agreement matrices, Electronic Supplement, Tables S2) rather than commission with undisturbed forest. Thus, in the future focus can be on improving separation of the disturbance agents, particularly those that occur less frequently (Table 2). 
That said, care must also be taken to improve separation of subtler disturbances (e.g. stress and wind) from stable forest, as the scenes with the highest prevalence of these agents (e.g. p16r37, p35r32, p41r29) also had the highest rates of stable forest commission error.

Prior to conducting this study, one area of uncertainty was whether modeling causal agents directly would negatively impact the detection of unattributed disturbance (i.e. binary disturbed/not disturbed forest). Our results (Table 4) showed that causal agent models perform as well, or slightly better than models which directly predict binary disturbance, thus it may not be necessary to model disturbance prior to assigning causality. This finding is further reinforced by the fact that the global forest change and VCT disturbance maps were not found to be important predictors of causality in our agent models (Figure 6). Moving forward it useful to know that empirical models can focus on prediction of causality without sacrificing detection of more general disturbance patterns.

\subsection{Disturbance year assignment}

Although the rule-based model used in step two of our approach performed well for abruptly occurring change agents, it did struggle to assign the proper onset year of subtler changes such as stress and wind. (Figure 5a). This is not entirely surprising as the temporal onset of gradual, longer occurring stress disturbances are difficult to quantify even with high resolution imagery. In addition, the non-linear spline functions (e.g. vee and invented vee shapes, Figure 2) used to assign disturbance years to areas of predicted stress, tended to find breakpoints in the spectral response prior to actual event occurring in the forest canopy. Although we attempted to adjust the change points to account for this lag, our 
adjustments were clearly insufficient, as the annual rates of stress were on average underestimated by 10 or more years. For example, in p35r32 our predicted stress rate peaked in 1995 (Figure 7d), however the Colorado State Forest Service (CSFS) estimates that in this area mortality from mountain pine beetle actually peaked in 2008 (Colorado State Forest Service, 2015). While this lack of temporal agreement is disappointing, we do note that our predictions did yield a similar bell shaped pattern as the CSFS estimates, thus there is hope that more realistic temporal patterns can be resolved with additional modifications to the shape-fitting algorithm.

Despite these challenges our rule-based model did perform well when viewed as a percentage of all disturbances from across all ten scenes (Figure 5b). As $88 \%$ of the correctly classified agents received a year that was within \pm 2 years of the reference date, the approach was sufficiently accurate to allow quantification of highly realistic temporal patterns of disturbance for most agent classes. Further analysis revealed that many of the largest temporal discrepancies occurred on plots with more than one disturbance, thus it's likely many of the errors were the result of the shape-fitting algorithm detecting a secondary disturbance instead of the greatest magnitude change as was intended. Therefore, expanding our approach to include multiple disturbances (e.g. see double jump shape in Moisen et al., 2016) may help improve temporal assignment accuracy in future applications.

4.3. Predictor variable importance 
Correlation plots (see Electronic Supplement, Figure S2) showed that several of the individual predictor variables were strongly related, thus a rank scoring system was used to gauge the relative importance of the five groups of predictors (i.e. spectral metrics, patch geometry, forest occurrence, disturbance and topography) used in the RF models. Although variables from all 5 predictor groups were deemed important in at least one scene-level model, our results showed that the MTBS (disturbance group) and change magnitude (spectral metric group) variables were by far the most important predictors (Figure 6). In the western region, where fires were larger and occurred more frequently, MTBS helped separate fires from other disturbance agents with similar change magnitudes. For example, in p45r30 the MTBS predictor helped reduce false predictions of fire in areas of low intensity, partial harvesting (e.g. see black arrows, bottom panel Figure 8h). There was a tradeoff however, as employing MTBS as predictor also resulted in fewer harvest predictions inside the MTBS burn perimeters (e.g. see black arrow, top panel Figure 8h). In the east, using MTBS as a predictor helped overcome a paucity of fire reference samples (Table 2), which ultimately allowed our RF models to spatially predict some fire in known locations (e.g. see p14r32, p16r37 and p24r27, Electronic Supplement, Figure S1). Although we decided to use MTBS as a predictor, the process is flexible, thus future applications can weigh these costs when determining how best to leverage national datasets in predictive disturbance models.

The change magnitude spectral metrics were also found to be important predictors of disturbance causality (Figure 6), however due to the strong linear relationship among these variables (see Electronic Supplement, Figure S2) we do not draw any formal 
conclusions as to which specific measure (i.e. absolute or relative) or spectral region (i.e. B5, FI, NDVI and NBR) contributed the most to the RF models. Nonetheless, it is clear that all four spectral bands/indices contributed useful information to the RF models and that change magnitude is the spectral variable most strongly related to disturbance causality. Though the patch geometry, forest occurrence, and topography predictor groups were generally less important they did contribute significant information to a few of the scenelevel RF models (Figure 6). Aside from patch geometry, these variables tended to be less correlated with the other predictor groups (see Electronic Supplement, Figure S2), thus they did offer unique information, which was occasionally important depending on the region of interest (e.g. elevation was important in two western scenes with mountainous topography).

\subsection{Spatiotemporal patterns of forest disturbance agents}

\subsubsection{Annual rates of disturbance}

Reliably separating disturbed and undisturbed areas (Table 4) allowed accurate characterization of regional and landscape scale disturbance dynamics occurring across the ten Landsat test scenes. Quantifying annual rates separately for each agent type (Figure 7ae) allowed cyclically episodic events (e.g. Fire, Figure 7b) to be quantified and assessed separately from less frequently occurring events like hurricanes (e.g. Wind, p16r37 Figure 7e). Despite some inaccuracies in assigning timing to the subtler change types (e.g. stress and wind, see Figure 5a), the agent specific temporal profiles revealed interesting differences between natural events, which tended to cause distinct pulses of change (e.g. Fire Figure 7b, Stress Figure 7d and Wind Figure 7e), versus human driven events, which 
were often more consistent and steady through time (e.g. Conversion Figure 7a, Harvest Figure 7c).

A closer look reveals most of the temporal patterns resolved by our approach are in strong agreement with extant data. For example, the average peak year of conversion from our model estimates is $1995 \pm 4$ years (see Electronic Supplement, Figure S3), which is in strong agreement with the 1994 peak in urban sprawl estimated by Barrington-Leigh and MillardBall (2015) and the 1992-1997 peak in forest lost to development taken from the 2010 Natural Resources Conservation Service (NRCS), National Resources Inventory (NRI) report. In p45r30, predicted rates of harvesting generally agree with timber harvest records reported by the Oregon Department of Forestry (see Gale et al., 2012), which show that most federal land owners significantly ramped up harvesting just prior to the 1994 Northwest Forest Plan, while non-federal owners showed no apparent trend before or after the policy was enacted (see Electronic Supplement, Figure S4). Rates of stress were well aligned with the recent forest decline rate reported by Cohen et al. (2016). Although our model results and those from Cohen et al. (2016) show broadly similar rates of stress ( $2.0 \% / y r)$, our estimates peak much to early due to the non-linear shape models (Figure 2), which were used to assign timing to our predicted disturbances (discussed above in section 4.2.). In p16r37 our modeled rates of wind and harvest were well aligned with Forest Service research (e.g. see Sheffield and Thompson, 1992 and Hook et al., 2009) showing high rates of wind damage and salvage logging occurred immediately after Hurricane Hugo made land fall in 1989 (captured here in 1990 due to the timing of available imagery). 


\subsubsection{Spatial patterns of disturbance}

Despite varying levels of pixel-level agreement (Figures 3 and 4) the developed causal agent maps resolved highly realistic spatial depictions of the five causal agent classes. One important outcome was our ability to separate conversion (or forest lost to other land uses) from other anthropogenic disturbances such as forest harvesting (e.g. see conversion, Figure 8a, $\mathrm{d}$ and e). Although the area converted each year was quite small, the long term effects are much more persistent than for other disturbance types. For example, our estimates suggest that across the ten test scenes $2,150 \mathrm{~km}^{2}$ (or 830 square miles) of forest was lost to other land uses during the 26-year period of our study. Although most of these areas represent permanent and/or long term shifts away from predominate forest cover, we do recognize a small portion will become revegetated (e.g. through surface mining reclamation) and thus, will need to be reexamined in the future to determine if forest conditions are eventually regained.

Given the comprehensive quality of MTBS we wanted our fire maps to be in line with this high quality data set, yet still have the flexibility of picking up smaller fires, which were less than its minimum mapable size threshold (i.e. 405 ha in the west and 202 ha in the east). Of the 712 fire reference plots (Table 2), only 96 were from non-MTBS fires, mostly brought in from the LANDFIRE supplemental training data. Overall, our models correctly classified $40 \%$ of these smaller fires compared to $94 \%$ of the MTBS fires. Considering only $13 \%$ of the fire reference plots contained smaller, non-MTBS fires, this level of performance is not entirely unexpected, however it does underscore the need for more reference samples, 
especially given that many of the rarer disturbance types (e.g. fire and stress in the east and conversion in the west) were underrepresented by our probabilistic stratified sampling approach.

Harvest maps resolved interesting spatial patterns, such as in p12r28, where roughly similar harvesting rates in the U.S. and Canada have led to noticeably different spatial patterns of disturbance (see Electronic Supplement, Figure S5). For example, the larger cut blocks used on the U.S. side have, over time, produced a more contiguously fragmented landscape compared to the Canadian side, where smaller, more dispersed cut blocks have yielded more diffuse spatial patterns. Similar spatial patterns were also seen in p45r30, where lower annual harvesting rates on U.S. Forest Service (USFS) lands have resulted in more distributed patches, compared to the larger isolated areas of intensively cutover forest typically found on private (Figure $8 \mathrm{~g}$ ).

Maps of stress, although not highly accurate at the pixel scale (Figure 4), did yield realistic spatial depictions which were mostly in good agreement with the aerially acquired IDS data (Figure 8b). Although the percentage of spatial alignment was relatively low (p35r32 $=45 \%, \mathrm{p} 41 \mathrm{r} 29=22 \%$ and $\mathrm{p} 36 \mathrm{r} 37=8 \%$ ) caution should be taken as the IDS data are polygon-based, and thus represent only a partial indicator of insect activity for a given year (Meddens et al., 2012). Wind, which was mainly observed in p16r37, was found to be in relatively good agreement with a Landsat disturbance map, specifically aimed at quantifying the impacts of Hurricane Hugo on migratory bird habitat (see Rittenhouse et al., 2010 and http://earthobservatory.nasa.gov/IOTD/view.php?id=43382). Figure $8 \mathrm{f}$ 
shows that both the previously published map (in brown) and the wind predictions from our model (in pink) fell mostly to the right of the hurricane track.

\subsection{National implementation and future improvements}

One of the main outcomes of this study is the improved knowledge of our capacity to model different forest disturbance agents, which can now be extended to the rest of the country. Moving forward one of the biggest challenges will be collecting enough reference data at the national scale to sufficiently capture rare disturbance events. The fact a stratified sample fell short of suitably capturing all the disturbance agents in our scene-based study (e.g. lack of conversion, stress and wind in the east and conversion and stress in the west) reinforces how much data will be needed nationally, especially considering that over the last quarter century nearly two thirds of U.S. forests remained undisturbed (e.g. see http://landsat.gsfc.nasa.gov/?p=11565). This issue is further compounded when reference plots are distributed randomly across the landscape, which is preferred for ease of statistical estimation, yet problematic for capturing rare classes. Probabilistic samples also tend to have more noise as they often fall on edges and transitional boundaries (resulting in mixed pixels), which in turn makes them more difficult to classify correctly. As our study demonstrates potential exists to farm supplemental training data from other outside data sources, however there will always be a need for probability-based samples as they form the basis for assessing map quality (Olofsson et al., 2014) and for producing design-based statistical estimates (e.g. see Schroeder et al., 2014 and Cohen et al., 2016). The importance and need for annual reference data is readily apparent as efforts are already underway to collect a nationally consistent, inter-agency time series reference data set which, along with 
the Landsat archive will form the basis for several federal land change monitoring programs (e.g. U.S. Forest Service - Landscape Change Monitoring System (LCMS, https://www.fs.fed.us/rmrs/groups/landscape-change-monitoring-system-lcms-scienceteam and U.S. Geological Survey - Land Change Monitoring, Analysis and Projection (LCMAP, http://www.earthobservations.org/documents/meetings/201605_lcc/201605_lcc_usgs_cli mate_land_use_change.pdf).

Once enough data have been collected the next issue will be the scalability of the RF models to new areas. Here we developed and applied models directly to individual Landsat scenes, however as we begin modeling over larger spatial domains inevitably models will have to extrapolated into areas where no reference data are available. Initial testing using data from this study suggests that both mixing data from different scenes and applying data to new unseen areas will undoubtedly change the amount of disturbance predicted by RF. In fact, our observation was that RF seems rather sensitive to changes in input training data and spatial predictor data, thus some experimentation will be needed to determine the appropriate spatial domain for developing and applying models over larger areas (e.g. by ecoregions, mapping zones, etc.). Deriving the necessary national scale predictor variables will also take some computational effort, especially for time series algorithms which iteratively fit statistical models to every Landsat pixel. Here we used output from our shape-fitting algorithm, as well as from VCT and the global forest change product as predictor variables in our RF models. In the future, including metrics derived from other change detection algorithms (e.g. LandTrendr - Kennedy et al., 2010; CCDC - Zhu et al., 
2010) may help improve results. Our analysis of predictor variable importance, clearly showed that the spectral disturbance metrics often had the most predictive power, especially those related to change magnitude. Interestingly the most important spectral metric tended to vary for each test scene, further reinforcing the need to use metrics derived from multiple spectral bands and vegetation indices.

Future improvements, include updating the shape-fitting algorithms ability to capture the acceleration point of subtle disturbances which should help yield more accurate temporal estimates of when insect and disease outbreak begin. Another future improvement would be the addition of a double jump shape, which can capture multiple disturbances in one trajectory (e.g. see Moisen et al., 2016). Capturing subtle changes before and after higher magnitude events will remain challenging, however with more frequent observations coming from new (e.g. Sentinel-2) and future (e.g. Landsat 9 and 10) moderate resolution earth observing satellites there will soon be even more data available to fill image gaps, which in turn should help resolve the timing of consecutive disturbance events. On the other hand, expanding prediction to include multiple disturbance classes will also further heighten the need for more reference data. Given that only $8 \%$ of our 2,400 stratified reference plots contained more than one disturbance and some agents occurred at rates less than $0.05 \%$ annually (e.g. see conversion, Figure 7a), it will likely require large sample sizes (if simple random sampling is used) or explicit targeting through some combination of stratified and purposive sampling to adequately capture certain types of disturbance.

\section{Conclusion}


The presented two-step modeling approach yielded highly informative annual estimates of several different types of causal agents affecting U.S. forests. The time series shape-fitting algorithm produced highly informative change metrics for multiple Landsat spectral inputs, which proved to be important predictors of different types of disturbance. The results indicate that at the pixel-scale, both the temporally indifferent predictions of causal agents (Electronic Supplement, Table S2, and Figure 4) and the rule-based assignment of disturbance year (Figure 5) were in good agreement with the reference data. In fact, when sufficient reference data were available for training and model testing, five different types of forest disturbance (conversion, fire, harvest, stress and wind) could be accurately separated from stable (undisturbed) forest, leading to improved spatial and temporal characterizations of when and where different agents are impacting the forested landscape. Although this study involved a limited number of test sites, the forest types and disturbance regimes tested were sufficiently diverse to allow guidance on several issues which may potentially affect future national disturbance mapping efforts (e.g. reference data collection, empirical modeling criteria, predictor variable importance, expected accuracies and potential usage of spatial and temporal causality outputs). Future work will focus on improving the spectral characterization of change captured by the shape-fitting algorithm, as well as the collection of a nationally consistent reference data set, which can facilitate seamless monitoring of land use and land cover changes occurring across all cover types, including non-forest.

\section{Acknowledgements}


This research was funded by NASA's Terrestrial Ecology Program through the North American Forest Dynamics (Phase 3) project and NASA's Carbon Cycle and Ecosystems Focus Area (NNH11AR29I). Additional support was provided by the U.S. Forest Service Geospatial Technology Applications Center (GTAC) and the Interior West Region of the U.S. Forest Service, Forest Inventory and Analysis (FIA) program. We also gratefully acknowledge assistance provided by the scientists and staff at NASA's Earth Exchange (NEX) and the University of Maryland, as well as the TimeSync interpretation team at Oregon State University's Laboratory for Applications of Remote Sensing in Ecology (LARSE). The corresponding author also wishes to recognize contributions by ASRC Federal InuTeq and the USGS Landsat program.

\section{References}

Allen, C.D., Macalady, A.K., Chenchouni, H., Bachelet, D., McDowell, N., Vennetier, M., Kitzberger, T., Rigling, A., Breshears, D.D., Hogg, E.H. (Ted), Gonzalez, P., Fensham, R., Zhang, Z., Castro, J., Demidova, N., Lim, J-H., Allard, G., Running, S.W., Semerci, A., and Cobb, N. (2010). A global overview of drought and heat-induced tree mortality reveals emerging climate change risks for forests. Forest Ecology and Management, 259, 660684.

Anderegg, W.R.L., Kane, J.M., \& Anderegg, L.D.L. (2013). Consequences of widespread tree mortality triggered by drought and temperature stress. Nature Climate Change, 3, 30-36.

Aral, M.M. (2014). Climate change and persistent high temperatures: does it matter? Frontiers in Environmental Science, 2(45), 1-8.

Barrington-Leigh, C., \& Millard-Ball, A. (2015). A century of sprawl in the United States. Proceedings of the National Academy of Sciences, 112(27), 8244-8249.

Beers, T.W., Dress, P.E., \& Wensel, L.C. (1966). Aspect transformation in site productivity research. Journal of Forestry, 64, 691.

Blackard, J., Finco, M., Helmer, E., Holden, G., Hopppus, M., Jacobs, D., et al. (2008). Mapping U.S. forest biomass using nationwide forest inventory data and moderate resolution information. Remote Sensing of Environment, 112, 1658-1677. 
Breiman, L. (2001). Random Forests. Machine Learning, 45(1), 5-32.

Brooks, E. B., Wynne, R. H., Thomas, V. A., Blinn, C. E., \& Coulston, J. W. (2014). On-the-fly massively multitemporal change detection using statistical quality control charts and Landsat data. IEEE Transactions on Geoscience and Remote Sensing, 52, 3316-3332.

Christiansen, E., Waring, R.H., \& Berryman, A.A. (1987). Resistance of conifers to bark beetle attack: Searching for general relationships. Forest Ecology and Management, 22, 89-106.

Cohen, W.B., Yang, Z., Stehman, S.V., Schroeder, T.A., Bell, D.M., Masek, J.G., Huang, C., \& Meigs, G.W. (2016). Forest disturbance across the conterminous United States from 1985-2012: The emerging dominance of forest decline. Forest Ecology and Management, $360,242-252$.

Cohen, W. B., Yang, Z., \& Kennedy, R. (2010). Detecting trends in forest disturbance and recovery using yearly Landsat time series: 2 . TimeSync - Tools for calibration and validation. Remote Sensing of Environment, 114, 2911-2924.

Colorado State Forest Service. 2015. Report on the Health of Colorado's Forests: 15 years of change. https://csfs.colostate.edu/media/sites/22/2016/02/ForestHealthReport-2015.pdf

Dale, V. H., Joyce, L. A., McNulty, S., Neilson, R. P., Ayres, M. P., Flannigan, M.D., Hanson, P.J., Irland, L.C., Lugo, A.E., Peterson, C.J., Simberloff, D., Swanson, F.J., Stocks, B.J., \& Wotton, M. (2001). Climate change and forest disturbances. BioScience, 51(9), 723-734.

Eidenshink, J., Schwind, B., Brewer, K., Zhu, Z. L., Quayle, B., \& Howard, S. (2007). A project for monitoring trends in burn severity. Fire Ecology Special Issue, 3, $3-21$.

Freeman, E.A., Moisen, G.,G., Coulston, J.W., \& Wilson, B.T. (2015). Random forests and stochastic gradient boosting for predicting tree canopy cover: comparing tuning processes and model performance. Canadian Journal of Forest Research, 45, 1-17.

Freeman, E.A., Frescino, T.S., \& Moisen, G.G. (2014). ModelMap: an R package for model creation and map production. https://cran.r-project.org/web/packages/ModelMap/vignettes/VModelMap.pdf

Freeman, E.A., Moisen, G.G., \& Frescino, T.S. (2012). Evaluating effectiveness of downsampling for stratified designs and unbalanced prevalence in Random Forest models of tree species distributions in Nevada. Ecological Modelling, 233, 1-10.

Foster, D.R. (1988). Species and stand response to catastrophic wind in central New England, USA. The Journal of Ecology, 76(1), 135-151. 
Gale, C.B., Keegan, C.E, Berg III, E.C., Daniels, J., Christensen, G.A., Sorenson, C.B., Morgan, T. A., \& Polzin, P. (2012). Oregon's forest products industry and timber harvest, 2008: Industry trends and impacts of the great recession through 2010. USDA Forest Service PNW-GTR-868. 55 pp.

Goward, S.N., Masek, J.G., Cohen, W, Moisen, G., Collatz, G.J., Healey, S., Houghton, R.A., Huang, C., Kennedy, R., Law, B., Powell, S., Turner, D. and Wulder, M.A. (2008). Forest disturbance and North American carbon flux. Eos Transactions, 89, 11, 105-106.

Gu, H., Williams, C.A., Ghimire, B., Zhao, F., and Huang, C. (2016). High-resolution mapping of time since disturbance and forest carbon flux from remote sensing and inventory data to assess harvest, fire and beetle disturbance legacies in the Pacific Northwest.

Biogeosciences, 13, 6321-6337.

Hansen, M. C., Potapov, P. V., Moore, R., Hancher, M., Turubanova, A., Tyukavina, A., Thau, D., Stehman, S.V., Goetz, S.J., Loveland, T.R., Kommareddy, A., Egorov, A., Chini, L., Justice, C.O., \& Townshend, J.R.G. (2013). High-resolution global maps of 21st-century forest cover change. Science, 342, 850-853.

Haywood, A., Verbesselt, J., \& Baker, P.J. (2016). Mapping disturbance dynamics in wet sclerophyll forests using time series Landsat. International Archives of the Photogrammetry, Remote Sensing and Spatial Information Sciences, XLI-B8, 633-641, doi:10.5194/isprs-archives-XLI-B8-633-2016.

Hermosilla, T., Wulder, M.A., White, J.C., Coops, N.C., \& Hobart, G.W. (2015). Regional detection, characterization, and attribution of annual forest change from 1984 to 2012 using Landsat-derived time-series metrics. Remote Sensing of Environment, 170, 121132.

Hook, D.D., Buford, M.A., \& Williams, T.M., (2009). Impact of Hurricane Hugo on the South Carolina coastal plain forest. In J.L. Haymond, D.D. Hook \& W.R. Harms (Eds.), Hurricane Hugo: South Carolina forest land research and management related to the storm. USDA Forest Service GTR SRS-5. 540 pp.

Huang, C., Goward, S. N., Masek, J. G., Thomas, N., Zhu, Z., \& Vogelmann, J. E. (2010a). An automated approach for reconstructing recent forest disturbance history using dense Landsat time series stacks. Remote Sensing of Environment, 114, 183-198.

Huang, C., Thomas, N., Goward, S. N., Masek, J. G., Zhu, Z., Townshend, J. R. G., \& Vogelmann, J. E. (2010b). Automated masking of cloud and cloud shadow for forest change analysis. International Journal of Remote Sensing, 31, 5449-5464.

Huang, C., Goward, S. N., Masek, J. G., Gao, F., Vermote, E. F., Thomas, N., Schleeweis, K., Kennedy, R. E., Zhu, Z., Eidenshink, J. C., \& Townshend, J. R. G. (2009). Development of time series stacks of Landsat images for reconstructing forest disturbance 
history. International Journal of Digital Earth, 2, 195-218.

Huang, C., Song, K., Kim, S., Townshend, J. R. G., Davis, P., Masek, J. G., \& Goward, S. N. (2008). Use of a dark object concept and support vector machines to automate forest cover change analysis. Remote Sensing of Environment, 112, 970-985.

Intergovernmental Panel on Climate Change (2014). Climate change 2013: The physical science basis. In T. F. Stocker, D. Qin, G. -K. Plattner, M. Tignor, S. K. Allen, J. Boschung, A. Nauels, Y. Xia, V. Bex, \& P.M. Midgley (Eds.), Contribution of Working Group 1 to the fifth assessment report of the Intergovernmental Panel on Climate Change. Cambridge, UK and New York, NY, USA: Cambridge University Press.

Kennedy, R.E., Yang, Z., Braaten, J., Copass, C., Antonova, N., Jordan, C., \& Nelson, P. (2015). Attribution of disturbance change agent from Landsat time-series in support of habitat monitoring in the Puget Sound region, USA. Remote Sensing of Environment, 166, 271285.

Kennedy, R. E., Yang, Z., \& Cohen, W. B. (2010). Detecting trends in forest disturbance and recovery using yearly Landsat time series: 1 . LandTrendr - Temporal segmentation algorithms. Remote Sensing of Environment, 114, 2897-2910.

Kennedy, R.E., Cohen, W.B., \& Schroeder, T.A. (2007). Trajectory-based change detection for Automated characterization of forest disturbance dynamics. Remote Sensing of Environment, 110, 370-386.

Key, C. H., \& Benson, N. C. (2005). Landscape assessment: Remote sensing of severity, the Normalized Burn Ratio. FIREMON: Fire effects monitoring and inventory system. In D. C. Lutes (Ed.), USDA Forest Service General Technical Report RMRS-GTR-164-CD. Ogden, UT. (pp. LA1-LA51).

Linn, R., Winterkamp, J., Edminster, C., Colman, J.J., \& Smith, W.S. (2007). Coupled influences of topography and wind on wildland fire behaviour. International Journal of Wildland Fire, 16, 183-195.

Masek, J. G., Goward, S. N., Kennedy, R. E., Cohen,W. B., Moisen, G. G., Schleeweis, K., \& Huang, C. (2013). United States forest disturbance trends observed using Landsat time series. Ecosystems, 16, 1087-1104.

Masek, J. G., Vermote, E. F., Saleous, N. E., Wolfe, R., Hall, F. G., Huemmrich, K. F., Feng, G., Kutler, J., \& Teng-Kui, L. (2006). A Landsat surface reflectance dataset for North America, 1990-2000. IEEE Geoscience and Remote Sensing Letters, 3, 68-72.

McGarigal, K., Cushman, S.A., \& Ene, E. (2012). FRAGSTATS v4: Spatial pattern analysis program for categorical and continuous maps. University of Massachusetts, Amherst. http://www.umass.edu/landeco/research/fragstats/fragstats.html 
McRoberts, R. E., Wendt, D.G., \& Liknes, G. C. (2005). Stratified estimation of forest inventory variables using spatially summarized stratifications. Silva Fennica, 39(4), 559-571.

Meddens, A.J.H., Hicke, J.A., Ferguson, C.A. (2012). Spatiotemporal patterns of observed bark beetle-caused tree mortality in British Columbia and the western United States. Ecological Applications. 22, 1876-1891.

Mellor, A., Boukir, S., Haywood, A., \& Jones, S. (2015). Exploring issues of training data Imbalance and mislabeling on random forest performance for large area land cover Classification using the ensemble margin. ISPRS Journal of Photogrammetry and Remote Sensing, 105, 155-168.

Meyer, M.C., Liao, X., Freeman, E.A. \& Moisen, G.G. (2015). ShapeSelectForest: Shape selection for Landsat time series of forest dynamics. CRAN package version 1.1.

Meyer, M.C. (2013). A simple new algorithm for quadratic programming with applications in statistics. Communications in Statistics - Simulation and Computation, 42(5), 11261139.

Meyer, M.C. (2008). Inference using shape-restricted regression splines. Annals of Applied Statistics, 2(3), 1013-1033.

Mikkelson, K.M., Dickenson, E.R.V., Maxwell, R.M., McCray, J.E., \& Sharp, J.O. (2013). Waterquality impacts from climate-induced forest die-off. Nature Climate Change, 3, 218-222.

Mikkelson, K.M., Maxwell, R.M., Ferguson, I., Stednick, J.D., McCray, J.E., \& Sharp, J.O. (2011). Mountain pine beetle infestation impacts: modeling water and energy budgets at the hillslope scale. Ecohydrology, 6(1), 64-72.

Moisen, G.G., Meyer, M.C., Schroeder, T.A., Toney, C.J., Liao, X., Schleeweis, K., \& Freeman, E.A. (2016). Shape selection in Landsat time series: A tool for monitoring forest dynamics. Global Change Biology.

Neigh, C.S.R., Bolton, D.K., Diabate, M., Williams, J.J., \& Carvalhais, N. (2014a). An automated approach to map the history of forest disturbance from insect mortality and harvest with Landsat time-series data. Remote Sensing, 6, 2782-2808.

Neigh, C.S.R., Bolton, D.K., Williams, J.J., \& Diabate, M. (2014b). Evaluating an automated approach for monitoring forest disturbances in the Pacific Northwest from logging, fire and insect outbreaks with Landsat time series data. Forests, 5, 3169-3198.

Olofsson, P., Foody, G.M., Herold, M., Stehman, S.V., Woodcock, C.E., \& Wulder, M.A. (2014). Good practices for estimating area and assessing accuracy of land change. Remote 
Sensing of Environment, 148, 42-57.

Oswalt, S.N., Smith, W.B., Miles, P.D., and Pugh, S.A. (2014). Forest Resources of the United States, 2012: A Technical Document Supporting the Forest Service 2015 Update of the RPA Assessment. USDA Forest Service GTR WO-91. U.S. Department of Agriculture, Forest Service, Washington Office, Washington, D.C., 218 pp.

Potapov, P.V., Turubanova, S.A., Tyukavina, A., Krylov, A.M., McCarty, J.L., Radeloff, V.C., \& Hansen, M.C. (2015). Remote Sensing of Environment, 159, 28-43.

Raftery, A. E., Li, N., Ševčiková, H., Gerland, P., \& Heilig, G. K. (2012). Bayesian probabilistic population projections for all countries. Proceedings of the National Academy of Sciences, 109(35), 13915-13921.

Reams, G.A., Brewer, C.K., \& Guldin, R.W. (2010). Remote sensing alone is insufficient for quantifying changes in forest cover. Proceedings of the National Academy of Sciences, 107(38), 145.

Rittenhouse, C.D., Pidgeon, A.M., Albright, T.P., Culbert, P.D., Clayton, M.K., Flather, C.H., Huang, C., Masek, J.G., \& Radeloff, V. (2010). Avifauna response to hurricanes: regional changes in community similarity. Global Change Biology, 16, 905-917.

Rouse, J. W., Hass, R. H., Schell, J. A., \& Deering, D. W. (1973). Monitoring vegetation systems in the Great Plains with ERTS. 3rd ERTS Symposium, NASA SP-351, 1. pp. 309-317.

Ruefenacht, B., Finco, M. V., Nelson,M.D., Czaplewski, R., Helmer, E. H., Blackard, J. A., Holden, G.R., Lister, A.J., Salajanu, D., Weyermann, D., \& Winterberger, K. (2008). Conterminous U.S. and Alaska forest type mapping using Forest Inventory and Analysis data. Photogrammetric Engineering and Remote Sensing, 74(11), 1379-1388.

Schleeweis, K., Goward, S.N., Huang, C., Dwyer, J.L., Rishmawi, K., Lindsey, M.A., Michaelis, A. and Masek, J.G. (in press). Selection and quality assessment of Landsat data for the North American Forest Dynamics (NAFD) forest history maps of the U.S. International Journal of Digital Earth.

Schleeweis, K., Goward, S.N., Huang, C., Masek, J.G., Moisen, G., Kennedy, R.E., \& Thomas, N.E. (2013). Regional dynamics of forest canopy change and underlying causal processes in the contiguous U.S. Journal of Geophysical Research: Biogeosciences, 118, 1035-1053.

Schroeder, T.A., Healey, S.P., Moisen, G.M., Frescino, T.S., Cohen, W.B., Huang, C., Kennedy, R.E., \& Yang, Z. (2014). Improving estimates of forest disturbance by combining observations from Landsat time series with U.S. Forest Service Forest Inventory and Analysis data. Remote Sensing of Environment, 154, 61-73. 
Schroeder, T. A., Wulder, M.A., Healey, S. P., \& Moisen, G. G. (2012). Mapping wildfire and clearcut harvest disturbances in boreal forests with Landsat time series data. Remote Sensing of Environment, 115, 1421-1433.

Sheffield, R.M., \& Thompson, M.T. (1992). Hurricane Hugo effects on South Carolina's forest resources. USDA Forest Service GTR SE-284. 35 pp.

Spittlehouse, D.L., \& Stewart, R.B. (2003). Adaptation to climate change in forest management. BC Journal of Ecosystems and Management, 4(1), 1-11.

U.S. Department of Agriculture. (2013). Summary Report: 2010 National Resources Inventory, Natural Resources Conservation Service, Washington, DC, and Center for Survey Statistics and Methodology, Iowa State University, Ames, IA. http://www.nrcs.usda.gov/Internet/FSE_DOCUMENTS/stelprdb1167354.pdf

van Mantgem, P. J., Stephenson, N. L., Byrne, J. C., Daniels, L. D., Franklin, J. F., Fulé, P. Z., et al. (2009). Widespread increase of tree mortality rates in the Western United States. Science, 323(5913), 521-524.

Vogelmann, J. E., Xian, G., Homer, C., \& Tolk, B. (2012). Monitoring gradual ecosystem change using Landsat time series analyses: Case studies in selected forest and rangeland ecosystems. Remote Sensing of Environment, 122, 92-105.

Vogelmann, J.E., Kost, J.R., Tolk, B., Howard, S., Short, K., Chen, X., Huang, C., Pabst, K., \& Rollins, M.G. (2011). Monitoring landscape change for LANDFIRE using multi-temporal satellite imagery and ancillary data. IEEE Journal of Selected Topics in Applied Earth Observation and Remote Sensing, 4(2), 252-264.

Weed, A. S., Ayres, M. P., \& Hicke, J. (2013). Consequences of climate change for biotic disturbances in North American forests. Ecological Monographs, 83(4), 441-470.

Weiss, G.M. \& Provost, F. (2003). Learning when training data are costly: the effect of class Distribution on tree induction. Artificial Intelligence Research, 19, 315-354.

Westerling, A. L., Hidalgo, H. G., Cayan, D. R., \& Swetnam, T. W. (2006). Warming and earlier Spring increase western U.S. forest wildfire activity. Science, 313, 940-943.

Williams, C.A., Collatz, G.J., Masek, J., Huang, C., \& Goward, S.N. (2014). Impacts of disturbance history on forest carbon stocks and fluxes: Merging satellite disturbance mapping with forest inventory data in a carbon cycle model framework. Remote Sensing of Environment, 151, 57-71.

Williams, A.P., Allen, C.D., Millar, C.L., Swetnam, T.W., Michaelsen, J., Still, C.J., and Leavitt, S.W. (2010). Forest responses to increasing aridity and warmth in the southwestern United States. Proceedings of the National Academy of Sciences, 107(50), 21289-21294. 
Zhao, F.R., Meng, R., Huang, C., Zhao, M., Zhao, F.A., Gong, P., Yu, L., \& Zhu, Z. (2016.) LongTerm post-disturbance forest recovery in the greater Yellowstone ecosystem analyzed Using Landsat time series stack. Remote Sensing, 8(11), 898, doi:10.3390/rs8110898.

Zhu, K., Woodall, C.W., Ghosh, S., Gelfand, A.E., \& Clark, J.S. (2014). Dual impacts of climate change: forest migration and turnover through life history. Global Change Biology, 20, 251-264.

Zhu, Z., Woodcock, C. E., \& Olofsson, P. (2012). Continuous monitoring of forest disturbance using all available Landsat imagery. Remote Sensing of Environment, 122, 75-91.

\section{Table Captions}

Table 1. Description of the forest cover (from Vegetation Change Tracker, VCT Huang et al. 2010a), forest species groups (from Ruefenacht et al., 2008), and disturbance processes (from Schleeweis et al. 2013) found in each of the ten Landsat test scenes.

Table 2. The number of probabilistic (P) and supplemental (S) reference samples by agent class for each of the ten Landsat test scenes. Agents shaded in gray were not used in the Random Forest models.

Table 3. The date range and number of images in each test scene's Landsat time series.

Table 4. Overall agreement and kappa for binary disturbance models and for causal agent models generalized to the disturbed/not disturbed (DND) level. Models with the highest accuracy are denoted in bold italic.

\section{Figure Captions}

Figure 1. Location of the ten Landsat test scenes used in this study. The scene boundaries reflect the coincident area shared by all the images in each time series stack.

Figure 2. The six pre-defined "shape" patterns used in the shape-fitting algorithm. Shapes depict known spectral patterns caused by disturbance agents and mature undisturbed forests. Although examples are shown in units of Landsat band 5 reflectance, the shapes algorithm was also run on FI, NBR and NDVI.

Figure 3. Three levels of overall agreement derived using the out of bag (OOB) predictions from each test scenes Random Forest model.

Figure 4. Model-based errors of omission and commission for the five disturbance agents and stable forest.

Figure $5 \mathrm{a}$ and $\mathrm{b}$. Frequency histograms showing observed (from the reference data) minus predicted (from the rule-based model) year of disturbance plotted as a percentage of a.) 
each agent class, and b.) total disturbance from across the ten Landsat test scenes. Note only the correctly classified disturbance plots from step one $(n=1,639)$ are used in these graphs.

Figure 6. Predictor variable importance rank scores derived using the mean decrease in accuracy metrics from the ten scene-level Random Forest models. Scene-level rank scores are summarized by the east and west regions described in Table 1. A description of the predictor variables (x-axis) can be found in the Electronic Supplement, Table S1.

Figure 7a-e. Annual rates of a.) Conversion, b.) Fire, c.) Harvest, d.) Stress, and e.) Wind predicted for each of the ten Landsat test scenes.

Figure 8a-h. Examples of forest disturbance causal agent maps showing a.) Conversion along the Canadian border, b.) Stress in the Rocky Mountains, CO c.) Fires in central ID d.) Conversion in Phoenix, AZ, e.) Conversion in central MN, f.) Wind damage in SC and g.) Harvests in central OR. Inset h. highlights the spatial impact of using MTBS as a predictor variable in Random Forest. 